This item was submitted to Loughborough's Research Repository by the author.

Items in Figshare are protected by copyright, with all rights reserved, unless otherwise indicated.

\title{
Modeling and upscaling analysis of gas diffusion electrode-based electrochemical carbon dioxide reduction systems
}

\section{PLEASE CITE THE PUBLISHED VERSION}

https://doi.org/10.1021/acssuschemeng.0c07387

\section{PUBLISHER}

American Chemical Society (ACS)

\section{VERSION}

AM (Accepted Manuscript)

\section{PUBLISHER STATEMENT}

This paper was accepted for publication in the journal ACS Sustainable Chemistry \& Engineering and the definitive published version is available at https://doi.org/10.1021/acssuschemeng.0c07387

\section{LICENCE}

CC BY-NC-ND 4.0

\section{REPOSITORY RECORD}

Yang, Ziming, Da Li, Lei Xing, Hang Xiang, Jin Xuan, Shaoan Cheng, Eileen Yu, and Aidong Yang. 2020. "Modeling and Upscaling Analysis of Gas Diffusion Electrode-based Electrochemical Carbon Dioxide Reduction Systems". Loughborough University. https://hdl.handle.net/2134/16907155.v1. 
1 Modelling and upscaling analysis of gas diffusion electrode based electrochemical

\section{2 carbon dioxide reduction systems}

3 Ziming Yang ${ }^{a}, D L^{b, c}$, Lei Xing ${ }^{a}$, Hang Xiang ${ }^{b}$, Jin Xuanc, Shaoan Cheng ${ }^{d}$, Eileen Hao Yu ${ }^{b}, c^{*}$, Aidong Yang $^{a *}$

$4 \quad$ a Department of Engineering Science, University of Oxford, Parks Road, Oxford, OX1 3PJ, United Kingdom

5 bSchool of Engineering, Newcastle University, Newcastle Upon Tyne, NE1 7RU, United Kingdom

6 ' Department of Chemical Engineering, Loughborough University, LE11 3TU, United Kingdom

$7 \quad$ d State Key Laboratory of Clean Energy Utilization, Zhejiang University, Hangzhou, China

$8 *$ Corresponding authors. E-mail address:

$9 \quad$ aidong.yang@eng.ox.ac.uk;

10 e.yu@lboro.ac.uk

12 Abstract

13 As an emerging technology for $\mathrm{CO}_{2}$ utilisation, electrochemical $\mathrm{CO}_{2}$ reduction reaction (ECO2RR) systems 14 incorporating gas diffusion electrodes (GDE) have the potential to transform $\mathrm{CO}_{2}$ to valuable products efficiently 15 and environment-friendly. In this work, a two-dimensional multiphase model capturing the details of the 16 catalyst layer in a GDE that produces formate with by-products is established and quantitatively validated 17 against experimental data. This model is capable of describing the mixture gas and aqueous species 18 transportation, electron conduction processes and a series of interrelated chemical and electrochemical 19 reactions. Specific electrical energy consumption (SEEC) and product yield (PY) have been introduced and used 
to examine the GDE scalability and evaluate the system performance. The results predict the optimal values for

21 applied cathode potential and catalyst loading and porosity. The effect of inlet gas composition and velocity is

22 also evaluated. Moreover, this study predicts that the GDE is scalable as it retains a stable performance as its

23 geometrical surface area varies. This model together with the simulation findings contributes to the improved

24 understanding of $\mathrm{GDE}$-based $\mathrm{CO}_{2}$ conversion as needed for the future development towards successful 25 industrial applications.

26 Keywords

27 Electrochemical $\mathrm{CO}_{2}$ reduction; Gas diffusion electrode; Modelling; Scalability; Energy consumption; Yield;

28 Optimisation

29 1. Introduction

30 Electrochemical $\mathrm{CO}_{2}$ reduction reaction (ECO2RR) has recently emerged as one of the carbon capture and 31 utilisation ( $\mathrm{CCU}$ ) technologies, which transforms $\mathrm{CO}_{2}$ to valuable chemicals by consuming water and 32 electricity. ${ }^{1,2}$ Depending on the catalyst type, $\mathrm{CO}_{2}$ can be reduced to different products such as syngas, methane $33\left(\mathrm{CH}_{4}\right)$, formate $\left(\mathrm{HCOO}^{-}\right)$and ethyl alcohol $\left(\mathrm{C}_{2} \mathrm{H}_{5} \mathrm{OH}\right)$ in the cathodic compartment. ${ }^{1,3}$ Currently, its application 34 is significantly limited by the low current density, mainly owing to the large $\mathrm{CO}_{2}$ mass transfer resistance and 35 the undesirable competitive hydrogen evolution reaction (HER). ${ }^{1-5}$ Gas diffusion electrode (GDE) offers a 36 prospect to the improvement of the overall performance of an ECO2RR electrolyser under mild operating 37 conditions (i.e. room temperature and ambient pressure). ${ }^{1,4}$

Different from the most frequently adopted conventional two-chamber electrolyser, where $\mathrm{CO}_{2}$ is purged into 39 the cathode chamber ${ }^{4}$ or supplied via the $\mathrm{CO}_{2}$-saturated catholyte ${ }^{3}$, the reactant gaseous $\mathrm{CO}_{2}$ is directly fed 40 into the gas chamber (GASC) and diffused through the gas diffusion layer (GDL) into the catalyst layer (CL). 
Compared to the planar electrode, the $\mathrm{CL}$ remarkably enlarges the specific area for ECO2RR reaction, alleviates

the mass transfer constraint of dissolved $\mathrm{CO}_{2}$ and reduces the ohmic loss by shortening the distance of reactant to the reaction sites and avoiding bubble appearance. ${ }^{1-3,6-9}$ Readers can refer to the literature that systematically reviewed the fundamental knowledge and development of GDE for more details. ${ }^{1}$ Despite of the moderate-to-high current densities achieved, ${ }^{10}$ there is much room for GDEs to become more competitive than their traditional counterparts (i.e. electrolyser for water splitting), eventually accomplishing successful. ${ }^{1,2,11}$

To date, most research on ECO2RR is dedicated to experimentally developing stable, efficient and selective catalysts. ${ }^{2}$ Limited attention has been paid to the optimisation of electrode configuration and operational conditions, ${ }^{9,12}$ and even fewer studies focus on upscaling. ${ }^{8,11,13-15}$ In addition to the experimental studies, modelbased analysis is instrumental to promote the transition from bench-scale research to industrial-scale applications. The first GDE model for the $\mathrm{CO}_{2}$ reduction process, a two-dimensional model of the cathode GDE in a continuous $\mathrm{CO}_{2}$ electrolyser for formate production, was constructed on the basis of Li \& Oloman cathodic model ${ }^{13}$ by introducing fluid dynamics and more sophisticated electrochemical kinetics. ${ }^{16}$ Subsequently, a fullcell model comprising both anode and cathode GDEs for converting $\mathrm{CO}_{2}$ to $\mathrm{CO}^{17}$ was proposed. These studies treated the whole GDE as a single porous medium and assumed that gaseous $\mathrm{CO}_{2}$ was able to be adsorbed onto the catalyst and react with the electrolyte directly, yet to reflect the experimental findings that only dissolved $\mathrm{CO}_{2}(\mathrm{aq})$ is the active reactant for electrochemical reactions. ${ }^{4}$ In 2016 , a full-cell model for electrochemical conversion of $\mathrm{CO}_{2}$ to formate was developed to integrate the multiphase flow in the catholyte, the $\mathrm{CO}_{2}$ adsorption process and transportation through membrane, which was then used in a scale-up analysis to assess the impact of cell height. ${ }^{18}$ Recently, a GDE model accounting for the local details of the CL was developed. ${ }^{3}$ Further work extended the model to include the anode and an investigation of the temperature and water variation for the membrane-electrode-assemblies (MEAs). ${ }^{19,20}$ However, restricted by the one-dimensional (1D) nature, the gas chamber in these studies was assumed isotropic, which ignored the spatial variation along the 
64 direction of the feed gas flow and, as recognised in previous work, ${ }^{3}$ may introduce inaccuracy in the predicted 65 current density distribution. Moreover, these proposed multiphysics models ${ }^{3,19,20}$ generally require further 66 experimental validation. These deficiencies would restrict the application of mathematical modelling in 67 systematically supporting the future development (including up-scaling) of GDE-based ECO2RR system.

68 In this paper, a two-dimensional steady-state multiphase GDE model describing inter- and intra-phase mass 69 transfer, electrochemical kinetics and aqueous-phase reactions is reported. The modelled system converts $\mathrm{CO}_{2}$ 70 to $\mathrm{CO}$ and formate with the latter selected as our target product due to its industrial importance and commercial 71 potential. ${ }^{5}$ Here, we present an experimental validation of our model, and subsequently use the model for 72 predicting the scalability of the GDE and the influence of several key parameters on the system's performance. 73 To the best of our knowledge, this is the first report of a GDE model for multiple $\mathrm{CO}_{2}$-reduction products with a 74 detailed account of reaction kinetics and mass transfer and applied to investigate the GDE scalability and 75 selectivity, which are both important for the industrial application of this technology. 
2. Model development and model-based evaluation

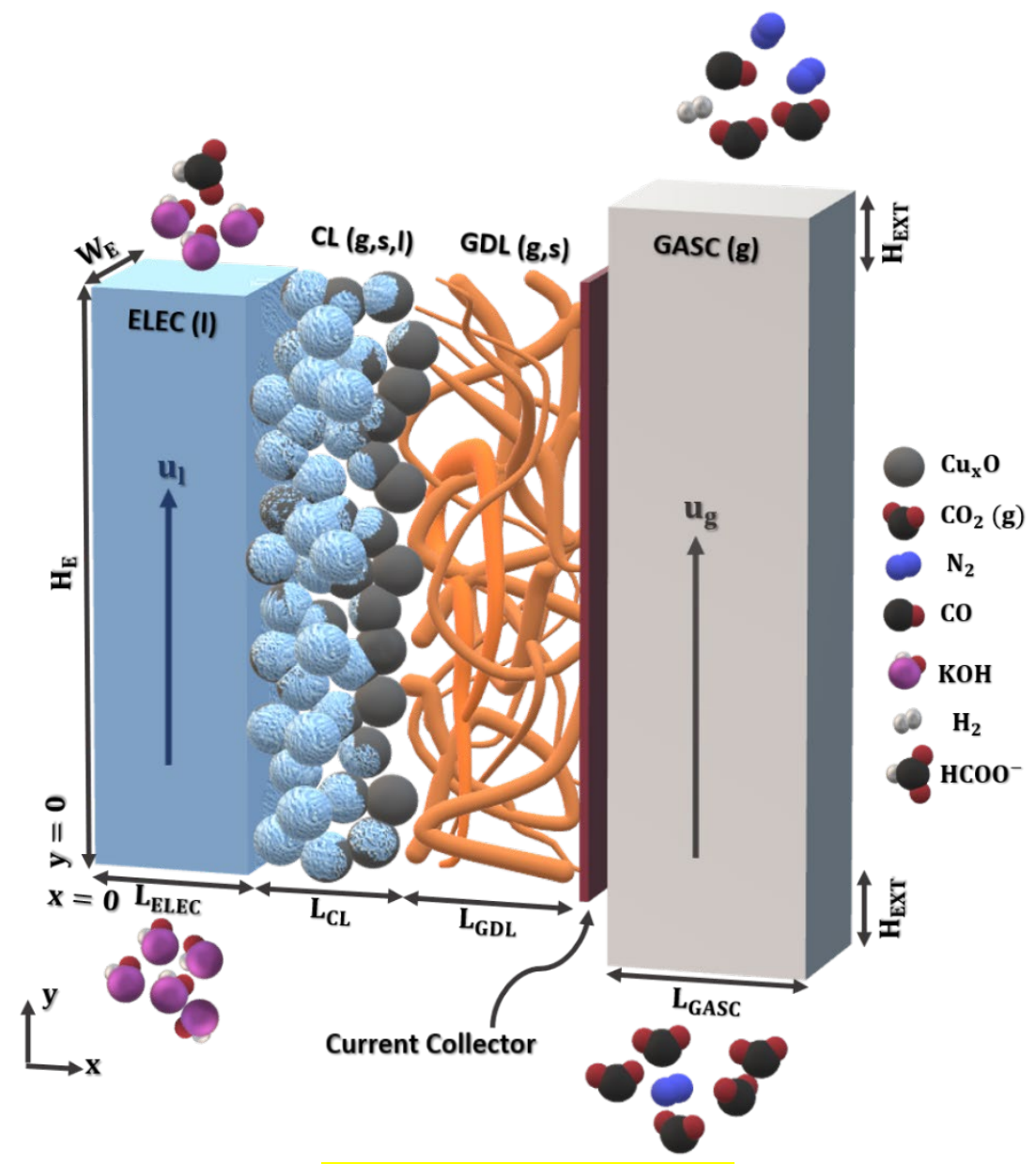

Figure 1 Schematic GDE model.

As shown in Figure 1, our GDE model comprises, from left to right, electrolyte channel (ELEC), CL, GDL and GASC.

They are parallel rectangular compartments with identical heights (y-axis) and widths but different thicknesses (x-axis). The feed gas is supplied into the system from the bottom of the GASC and escapes together with other gaseous products (i.e. $\mathrm{CO}, \mathrm{H}_{2}$ ) at the other side. The current collector ${ }^{4}$ between the GASC and the GDL, with negligible ohmic loss compared to the $\mathrm{GDL}$ and the $\mathrm{CL}$, serves the purpose of providing electrons. $\mathrm{CO}_{2}$ and electrons are transported via diffusion and conduction respectively through the porous hydrophobic GDL and react in the $\mathrm{CL}$. The GDL in our case is a single-layer GDL. ${ }^{21}$ As mentioned earlier, it is widely accepted that the dissolved $\mathrm{CO}_{2}(\mathrm{aq})$ is the only active reactant for electrochemical reactions, rather than $\mathrm{HCO}_{3}{ }^{-}, \mathrm{CO}_{3}{ }^{2-}$ or 
$\mathrm{CO}_{2}(\mathrm{~g}) \cdot{ }^{22-26}$ Thus, the gas-liquid mass transfer for $\mathrm{CO}_{2}$ and homogeneous (aqueous-phase) reactions which

consume $\mathrm{CO}_{2}(\mathrm{aq})$ in the $\mathrm{CL}$ should be considered. The $\mathrm{CL}$ is a layer coated with the granular catalyst of $\mathrm{Cu}_{\mathrm{x}} \mathrm{O}(\mathrm{a}$

mixture of $\mathrm{Cu}_{2} \mathrm{O}, \mathrm{CuO}$ and $\mathrm{Cu}$ ), a non-toxic and abundant choice attractive for upscaling and also with a promise

91 for the generation of multi-carbon products. ${ }^{4,27,28}$ The electrolyte (potassium hydroxide, $\mathrm{KOH}$ ) and the aqueous

92 products (i.e. formate) flow through the ELEC. In our case, two competing $\mathrm{CO}_{2}$ electrochemical reduction

93 reactions occur in the $\mathrm{CL}$ :

$$
\begin{gathered}
\mathrm{CO}_{2}(\mathrm{aq})+\mathrm{H}_{2} \mathrm{O}+2 \mathrm{e}^{-} \leftrightarrow \mathrm{HCOO}^{-}+\mathrm{OH}^{-} \\
\mathrm{CO}_{2}(\mathrm{aq})+\mathrm{H}_{2} \mathrm{O}+2 \mathrm{e}^{-} \leftrightarrow \mathrm{CO}+2 \mathrm{OH}^{-}
\end{gathered}
$$

94 In addition to $\mathrm{CO}_{2}$ reduction reactions, as mentioned earlier, an unwanted parasitic $\mathrm{HER}$ also takes place in the $95 \mathrm{CL}$ simultaneously. The HER in the alkaline condition is represented as:

$$
2 \mathrm{H}_{2} \mathrm{O}+2 \mathrm{e}^{-} \leftrightarrow \mathrm{H}_{2}+2 \mathrm{OH}^{-}
$$

96

\subsection{Gaseous species}

Gaseous species (i.e. $\mathrm{CO}_{2}(\mathrm{~g}), \mathrm{N}_{2}, \mathrm{H}_{2}$ and $\mathrm{CO}$ ) are considered in the GASC, the GDL and the CL; their mass conservation is modelled by Eq. (1). The mixture-averaged diffusion model is employed here to evaluate multicomponent diffusive fluxes without an excessive computational cost. ${ }^{3,19,20,30,31}$ The Soret effect is not considered in the diffusion term due to the isothermal assumption. ${ }^{32}$ 


$$
\nabla \cdot\left(-\rho_{\mathrm{g}} \mathrm{D}_{\mathrm{i}, \mathrm{m}} \nabla \omega_{\mathrm{i}}-\rho_{\mathrm{g}} \omega_{\mathrm{i}} \mathrm{D}_{\mathrm{i}, \mathrm{m}} \frac{\nabla \mathrm{M}_{\mathrm{g}}}{\mathrm{M}_{\mathrm{g}}}\right)+\nabla \cdot\left(\rho_{\mathrm{g}} \mathrm{u}_{\mathrm{g}} \omega_{\mathrm{i}}\right)=\mathrm{R}_{\mathrm{i}, \mathrm{m}}
$$

105 where i denotes the gaseous species; $\rho_{\mathrm{g}}$ represents the mixture gas density; $\omega_{\mathrm{i}}$ denotes the mass fraction of 106 gaseous species; $M_{g}$ is the averaged molar weight of mixture gas, which is calculated by $\left(\sum_{i} \frac{\omega_{i}}{M_{i}}\right)^{-1} ; M_{i}$ is the molar weight of gaseous species; $D_{i, m}$ is the diffusivity of each gaseous species in the medium, $m$; $u_{g}$ is mixture gas velocity. The source term $R_{i, m}$ for each species in the GASC and the GDL is zero; in the $C L$ it can be found in the SI Table S1.

The gaseous diffusivity, $\mathrm{D}_{\mathrm{i}, \mathrm{m}}$ is derived from the Maxwell-Stefan equation and simplified by assuming all other gaseous species have same velocities:

$$
D_{i, m}=\frac{1-\omega_{i}}{\sum_{k \neq i} \frac{X_{k}}{D_{i k}}}
$$

where $D_{i k}$ is the binary diffusivities for the species pairs present; $x_{k}$ denotes the molar fraction of gaseous species, k. In comparison with other mixture gas models such as Maxwell-Stefan, this assumption makes $\mathrm{D}_{\mathrm{i}, \mathrm{m}}$ to be determined by those parameters that are easily obtained..$^{30-32}$

The gas velocity, $\mathrm{u}_{\mathrm{g}}$ is solved by momentum balance together with overall mass balance. It is assumed that the gas mixture flow in the open channel of the GASC is laminar and compressible $(\mathrm{Ma}<0.3) .{ }^{17}$

$$
\begin{gathered}
\rho_{\mathrm{g}}\left(\mathrm{u}_{\mathrm{g}} \cdot \nabla\right) \mathrm{u}_{\mathrm{g}}=\nabla \cdot\left[-\mathrm{PI}+\mu_{\mathrm{g}}\left(\nabla \mathrm{u}_{\mathrm{g}}+\left(\nabla \mathrm{u}_{\mathrm{g}}\right)^{\mathrm{T}}\right)-\frac{2}{3} \mu_{\mathrm{g}}\left(\nabla \cdot \mathrm{u}_{\mathrm{g}}\right) \mathrm{I}\right]+\rho_{\mathrm{g} g} \\
\nabla \cdot\left(\rho_{\mathrm{g}} \mathrm{u}_{\mathrm{g}}\right)=0
\end{gathered}
$$
gravitational acceleration. 
119 In porous media of the GDL and the $\mathrm{CL}, \mathrm{D}_{\mathrm{i}, \mathrm{m}}$ in Eq. (1) is corrected for the effective porosity for gas, $\epsilon_{\mathrm{m}, \mathrm{g}}^{\mathrm{eff}}$ by using 120 the Bruggeman equation: ${ }^{3}$

$$
D_{i, m}^{\text {eff }}=\frac{1-\omega_{i}}{\sum_{k \neq i} \frac{X_{k}}{\left(\epsilon_{m, g}^{\text {eff }}\right)^{1.5} D_{i k}}}
$$

It is generally assumed that electrochemical reactions can only occur at the active sites in the $\mathrm{CL}$, where the electrolyte, the reactant and the catalyst meet, also regarding as three-phase interface. $3,16,17$ This requires the pores in the $C L$ to be partially or completely wetted. We define $S_{m}$ as the saturation coefficient, representing the ratio of liquid occupied volume to the total volume of the pores in the medium, $\mathrm{m}$. It is assumed that the factors affecting saturation (e.g. pore hydrophobicity and size distribution, capillary pressure, etc. ${ }^{3,33}$ ) remain unchanged and therefore the saturation coefficient is constant. The value of 0.5 is applied for the saturation coefficient in the $\mathrm{CL}, \mathrm{S}_{\mathrm{CL}}$ in our case (the detailed calculation method can be found in the SI section III). Same to the treatment in the prior modelling work, ${ }^{3} \mathrm{GDL}$ is assumed as completely dry (I.e. $\mathrm{S}_{\mathrm{GDL}}=0$ ). The relationship between $\epsilon_{\mathrm{m}, \mathrm{g}}^{\mathrm{eff}}$ and $\mathrm{S}_{\mathrm{m}}$ is:

$$
\epsilon_{\mathrm{m}, \mathrm{g}}^{\mathrm{eff}}=\epsilon_{\mathrm{m}}^{0}\left(1-\mathrm{S}_{\mathrm{m}}\right)
$$

where $\epsilon_{\mathrm{m}}^{0}$ represents the intrinsic porosity in the medium, $\mathrm{m}$, which is defined as the ratio of the total volume occupied by the pores and the total volume of the medium and assumed as constant and isotropic. $\epsilon_{\mathrm{CL}}^{0}$ is calculated by:

$$
\epsilon_{\mathrm{CL}}^{0}=1-\frac{\mathrm{m}_{\mathrm{cat}}}{\rho_{\mathrm{cat}} \mathrm{L}_{\mathrm{CL}}}
$$

where $m_{c a t}$ is the mass loading of catalyst (mass of catalyst per geometrical electrode surface area); $\rho_{\text {cat }}$ denotes the catalyst density. Neglecting any effect of bubbles, the pores in the $\mathrm{CL}$ are assumed to be occupied 
by a static liquid phase and the gas mixture with the effective porosity, $\epsilon_{\mathrm{m}, \mathrm{g}}^{\mathrm{eff}} \cdot 3,16$ Momentum balance for laminar 136 flow in the porous media becomes Darcy's law, in order to model mixture gas transport. $3,19,20,34$

$$
u_{g}=-\frac{\kappa_{m, g}^{\text {eff }}}{\mu_{g}}\left(\nabla P+\rho_{g} g\right)
$$

137

where $\kappa_{\mathrm{m}, \mathrm{g}}^{\mathrm{eff}}$ is the effective permeability for gas in the porous medium, $\mathrm{m}$. Its value for a Darcian flow in the $\mathrm{CL}$, which is assumed to be occupied by uniform spherical shape catalysts with a mono-disperse size distribution, is estimated by the Kozeny-Carman equation: ${ }^{35,36}$

$$
\kappa_{\mathrm{CL}, \mathrm{g}}^{\mathrm{eff}}=\frac{\mathrm{d}_{\mathrm{cat}}^{2}}{180} \frac{\left(\epsilon_{\mathrm{CL}, \mathrm{g}}^{\mathrm{eff}}\right)^{3}}{\left(1-\epsilon_{\mathrm{CL}, \mathrm{g}}^{\mathrm{eff}}\right)^{2}}
$$

where $d_{\text {cat }}$ is the diameter of catalyst particles. The effective permeability for the fibrous media, the GDL depends strongly on the intrinsic porosity and is given by: ${ }^{3,36-38}$

$$
\kappa_{\mathrm{GDL}, \mathrm{g}}^{\mathrm{eff}}=\frac{\kappa_{\mathrm{GDL}}^{0} \epsilon_{\mathrm{GDL}}^{0}{ }^{3}}{\left(1-\epsilon_{\mathrm{GDL}}^{0}\right)^{2}}\left(1-\mathrm{S}_{\mathrm{GDL}}\right)^{3}
$$

It is worth noting that the GDL may face the 'flooding' problem (i.e. electrolyte penetrates through the $\mathrm{CL}$ and goes into GDL) and become wetted in reality. ${ }^{1,12}$ In this case, the effective gaseous diffusivity (see Eqs. (5) and (6)) and permeability (see Eq. (10)) would decrease, potentially leading to poor GDE performance. Incorporating this detail would require modifications to the affected equations in the future.

The overall mass balance in the GDL and the $\mathrm{CL}$ is analogous to that of the GASC:

$$
\nabla \cdot\left(\rho_{\mathrm{g}} \mathrm{u}_{\mathrm{g}}\right)=\mathrm{Q}_{\mathrm{m}}
$$


where $Q_{m}$ is the source term, which is zero for the GDL and the sum of gaseous reaction rates in the $C L$ (see $S I$ 148 Table S1).

$149 \mathrm{~N}_{2}$ mass fraction is determined by following mass constraint:

$$
\sum \omega_{i}=1
$$

\subsection{Aqueous species \\ 2.3. Aqueous species}

The mass conservation of aqueous species, $\mathrm{j}$ is modelled by the Nernst-Plank equation Eq. (13):

$$
\nabla \cdot\left(-\rho_{1} D_{j, m} \nabla \omega_{j}-\frac{z_{j} F \rho_{l} \omega_{j} D_{j, m} \nabla V_{l}}{R_{\text {ideal }} T}+\rho_{1} \omega_{j} u_{l}\right)=R_{j, m}
$$

where $\rho_{\mathrm{l}}$ is the density of the liquid mixture; $z_{\mathrm{j}}$ is the valence of ionic species; $R_{\text {ideal }}$ is the ideal gas constant; $T$ is operating temperature; $\mathrm{u}_{1}$ is the liquid velocity, which is the ratio of volumetric flowrate to cross section area of the ELEC, $\mathrm{q}_{\mathrm{l}} / \mathrm{A}_{\mathrm{ELEC}} ; \mathrm{D}_{\mathrm{j}, \mathrm{m}}$ is the diffusivity of aqueous species and it is also corrected by the Bruggeman relationship in the porous medium, $\mathrm{m} .{ }^{39}$ The term of $\mathrm{R}_{\mathrm{j}, \mathrm{m}}$ in $\mathrm{CL}$ is listed in the $\mathrm{SI}$ Table $\mathrm{S} 1$.

\subsection{Homogenous reactions}

With fresh $\mathrm{KOH}$ as the electrolyte being continuously supplied and the $\mathrm{CL}$ being sufficiently thin, ${ }^{4}$ it is assumed that the $\mathrm{pH}$ (and hence the concentration of $\mathrm{OH}^{-}, \mathrm{C}_{\mathrm{OH}}$ ) in both the ELEC and the liquid phase in the $\mathrm{CL}$ maintain constant at the same value as feed concentration. Hereby we only consider homogeneous reactions under the alkaline condition:

$$
\begin{gathered}
\mathrm{CO}_{2}(\mathrm{aq})+\mathrm{OH}^{-} \stackrel{\mathrm{k}_{\mathrm{Ha}}}{\longrightarrow} \mathrm{HCO}_{3}{ }^{-} \\
\mathrm{HCO}_{3}{ }^{-}+\mathrm{OH}^{-} \stackrel{\mathrm{k}_{\mathrm{Hb}}}{\longrightarrow} \mathrm{H}_{2} \mathrm{O}+\mathrm{CO}_{3}{ }^{2-}
\end{gathered}
$$


Reaction rates for $\mathrm{Ha}$ and $\mathrm{Hb}$ are expressed as:

$$
\begin{aligned}
& \mathrm{R}_{\mathrm{Ha}}=\mathrm{k}_{\mathrm{Ha}} \mathrm{C}_{\mathrm{CO}_{2}(\mathrm{aq})} \mathrm{C}_{\mathrm{OH}}-\frac{\mathrm{k}_{\mathrm{Ha}}}{\mathrm{K}_{\mathrm{Ha}}} \mathrm{C}_{\mathrm{HCO}_{3}} \\
& \mathrm{R}_{\mathrm{Hb}}=\mathrm{k}_{\mathrm{Hb}} \mathrm{C}_{\mathrm{HCO}_{3}} \mathrm{C}_{\mathrm{OH}}-\frac{\mathrm{k}_{\mathrm{Hb}}}{\mathrm{K}_{\mathrm{Hb}}} \mathrm{C}_{\mathrm{CO}_{3}}
\end{aligned}
$$
transfer rate for $\mathrm{CO}_{2}$ is written as:

$$
\mathrm{R}_{\mathrm{P}, \mathrm{CO}_{2}(\mathrm{aq})}=-\mathrm{R}_{\mathrm{P}, \mathrm{CO}_{2}(\mathrm{~g})}=\mathrm{a}_{\mathrm{gl}} \mathrm{K}_{\mathrm{GL}_{\mathrm{L}}} \mathrm{M}_{\mathrm{CO}_{2}}\left(\frac{\mathrm{P}_{\mathrm{CO}_{2}(\mathrm{~g})}}{\mathrm{H}_{\mathrm{CO}_{2}}}-\mathrm{C}_{\mathrm{CO}_{2}(\mathrm{aq})}\right)
$$

where $\mathrm{a}_{\mathrm{gl}}$ is the specific gas-liquid interfacial area; $\mathrm{K}_{\mathrm{GL}}$ is the overall mass transfer coefficient; $\mathrm{H}_{\mathrm{CO}_{2}}$ is $\mathrm{Henry}^{\prime} \mathrm{s}$ constant for $\mathrm{CO}_{2}$ and has been calculated taking into account the salting-out effect (see $\mathrm{SI}$ section $\left.\mathrm{VII}\right) ; \mathrm{P}_{\mathrm{CO}_{2}}(\mathrm{~g})$ is the partial pressure of $\mathrm{CO}_{2}(\mathrm{~g})$, which is calculated according to Dalton's law: $\mathrm{P}_{\mathrm{CO}_{2}(\mathrm{~g})}=\mathrm{P}_{\mathrm{CL} \mathrm{X}_{\mathrm{CO}_{2}(\mathrm{~g})}}$; $\mathrm{C}_{\mathrm{CO}_{2}(\mathrm{aq})}$ is the concentration of dissolved $\mathrm{CO}_{2}$ in the electrolyte. $\mathrm{a}_{\mathrm{gl}}$ is given by (see $\mathrm{SI}$ section III): 


$$
\mathrm{a}_{\mathrm{gl}}=2 \frac{\epsilon_{\mathrm{CL}}^{0}\left(\mathrm{r}_{\mathrm{p}, \mathrm{CL}}-\delta_{\mathrm{ele}}\right)}{\mathrm{r}_{\mathrm{p}, \mathrm{CL}}{ }^{2}}
$$

obtained according to the Tafel kinetics: ${ }^{38}$

$$
\begin{gathered}
\mathrm{i}_{\mathrm{Ea}}=-\mathrm{i}_{\mathrm{O}, \mathrm{Ea}}^{\mathrm{ref}}\left(\frac{\mathrm{C}_{\mathrm{CO}_{2}(\mathrm{aq})}}{\mathrm{C}_{\mathrm{CO}_{2}(\mathrm{aq}), \mathrm{Ea}}^{\mathrm{ref}}}\right) \exp \left(-\frac{\beta_{\mathrm{Ea}} \mathrm{F}}{\mathrm{R}_{\text {ideal }} \mathrm{T}}\left(\mathrm{V}_{\mathrm{s}}-\mathrm{V}_{\mathrm{l}}-\mathrm{V}_{\mathrm{eq}, \mathrm{Ea}}^{\mathrm{ref}}\right)\right) \\
\mathrm{i}_{\mathrm{Eb}}=-\mathrm{i}_{\mathrm{O}, \mathrm{Eb}}^{\mathrm{ref}}\left(\frac{\mathrm{C}_{\mathrm{CO}_{2}(\mathrm{aq})}}{\mathrm{C}_{\mathrm{CO}_{2}(\mathrm{aq}), \mathrm{Eb}}^{\mathrm{ref}}}\right) \exp \left(-\frac{\beta_{\mathrm{Eb}} \mathrm{F}}{\mathrm{R}_{\text {ideal }} \mathrm{T}}\left(\mathrm{V}_{\mathrm{s}}-\mathrm{V}_{\mathrm{l}}-\mathrm{V}_{\mathrm{eq}, \mathrm{Eb}}^{\mathrm{ref}}\right)\right) \\
\mathrm{i}_{\mathrm{Ec}}=-\mathrm{i}_{\mathrm{O}, \mathrm{Ec}}^{\mathrm{ref}} \exp \left(-\frac{\beta_{\mathrm{Ec}} \mathrm{F}}{\mathrm{R}_{\text {ideal }} \mathrm{T}}\left(\mathrm{V}_{\mathrm{s}}-\mathrm{V}_{\mathrm{l}}-\mathrm{V}_{\mathrm{eq}, \mathrm{Ec}}^{\mathrm{ref}}\right)\right)
\end{gathered}
$$

179 where $\mathrm{i}_{\mathrm{O}, \mathrm{Ea}}^{\mathrm{ref}} \mathrm{i}_{\mathrm{O}, \mathrm{Eb}}^{\mathrm{ref}}$ and $\mathrm{i}_{\mathrm{O}, \mathrm{Ec}}^{\mathrm{ref}}$ are the exchange current densities per catalyst surface area at the reference condition; $\mathrm{C}_{\mathrm{CO}_{2}(\mathrm{aq}), \mathrm{Ea}}^{\mathrm{ref}}, \mathrm{C}_{\mathrm{CO}_{2(\mathrm{aq})} \text {, } \mathrm{Eb}}^{\mathrm{ef}}$ are the reference concentrations of $\mathrm{CO}_{2}(\mathrm{aq})$ corresponding to reaction (Ea) and (Eb), respectively; $\beta_{\mathrm{Ea}}, \beta_{\mathrm{Eb}}$ and $\beta_{\mathrm{Ec}}$ denote the symmetry factor corresponding to the formation of $\mathrm{HCOO}^{-}, \mathrm{CO}$ and $\mathrm{H}_{2}$, respectively; $\mathrm{F}$ is the Faraday constant; $\mathrm{V}_{\mathrm{eq}, \mathrm{Ea}}^{\mathrm{ref}}, \mathrm{V}_{\mathrm{eq}, \mathrm{Eb}}^{\mathrm{ref}}$ and $\mathrm{V}_{\mathrm{eq}, \mathrm{Ec}}^{\mathrm{ref}}$ are the equilibrium potentials for the reactions $(\mathrm{Ea})$ to $(\mathrm{Ec})$ in the reference condition and the operating temperature, respectively. The local electronic and electrolyte potential, $V_{s}$ and $V_{l}$ are derived by Ohm's law coupled with the charge conservation: ${ }^{17}$ 
186 where $\sigma_{\mathrm{s}, \mathrm{m}}^{\mathrm{eff}}$ and $\sigma_{\mathrm{l}, \mathrm{m}}^{\mathrm{eff}}$ are effective conductivities for solid material and electrolyte, respectively. Both of them 187 are assumed constant and are corrected for $\left(1-\epsilon_{\mathrm{m}}\right)$ and $\epsilon_{\mathrm{m}} \mathrm{S}_{\mathrm{m}}$ respectively in the porous media according to 188 the Bruggeman equation; ${ }^{39,43,44} \mathrm{Q}_{\mathrm{s}, \mathrm{m}}$ and $\mathrm{Q}_{\mathrm{l}, \mathrm{m}}$ are the source terms. $\mathrm{Q}_{\mathrm{s}, \mathrm{GDL}}$ and $\mathrm{Q}_{\mathrm{l}, \mathrm{ELEC}}$ are equal to zero due to 189 the absence of electrochemical reactions; in the $\mathrm{CL}$, they have same values but with opposite sign: ${ }^{3,38}$

$$
-\mathrm{Q}_{\mathrm{s}, \mathrm{CL}}=\mathrm{Q}_{\mathrm{l}, \mathrm{CL}}=\mathrm{a}_{\mathrm{sl}}\left(\mathrm{i}_{\mathrm{Ea}}+\mathrm{i}_{\mathrm{Eb}}+\mathrm{i}_{\mathrm{Ec}}\right)
$$

Electrochemical reaction rates for $\mathrm{CO}_{2}(\mathrm{aq}), \mathrm{HCOO}^{-}, \mathrm{CO}$ and $\mathrm{H}_{2}$ are expressed based on Faraday's law:

$$
\begin{aligned}
& \mathrm{R}_{\mathrm{E}, \mathrm{CO}_{2}(\mathrm{aq})}=\frac{\mathrm{M}_{\mathrm{CO}_{2}} \mathrm{a}_{\mathrm{sl}}\left(\mathrm{i}_{\mathrm{Ea}}+\mathrm{i}_{\mathrm{Eb}}\right)}{2 \mathrm{~F}} ; \mathrm{R}_{\mathrm{E}, \mathrm{HCOO}}=-\frac{\mathrm{M}_{\mathrm{HCOO}} \mathrm{a}_{\mathrm{Sl}} \mathrm{i}_{\mathrm{Ea}}}{2 \mathrm{~F}} ; \\
& \mathrm{R}_{\mathrm{E}, \mathrm{CO}}=-\frac{\mathrm{M}_{\mathrm{CO}} \mathrm{a}_{\mathrm{sl}} \mathrm{i}_{\mathrm{Eb}}}{2 \mathrm{~F}} ; \mathrm{R}_{\mathrm{E}, \mathrm{H}_{2}}=-\frac{\mathrm{M}_{\mathrm{H}_{2}} \mathrm{a}_{\mathrm{sl}} \mathrm{i}_{\mathrm{Ec}}}{2 \mathrm{~F}}
\end{aligned}
$$

191 where $\mathrm{M}_{\mathrm{HCOO}}, \mathrm{M}_{\mathrm{CO}}$ and $\mathrm{M}_{\mathrm{H}_{2}}$ are molecular weight for $\mathrm{HCOO}^{-}$, $\mathrm{CO}$ and $\mathrm{H}_{2}$, respectively.

$\mathrm{a}_{\mathrm{sl}}$ is the specific solid-liquid interfacial area and expressed as follows (see SI section III):

$$
\mathrm{a}_{\mathrm{sl}}=2 \frac{\epsilon_{\mathrm{CL}}^{0}}{\mathrm{r}_{\mathrm{p}, \mathrm{CL}}}
$$

\subsection{Boundary conditions}

The gaseous species in the GASC, the GDL and the $\mathrm{CL}$ are modelled collectively. At the inlet of the GASC, the mixture gas composition and velocity are set as identical to those of the inlet mixture gas. ${ }^{17}$ Ambient pressure (i.e.1atm) with non-diffusive species is set for the outlet mixture gas at the outlet of the GASC. Zero-flux for gaseous species is applied at the ELEC/CL interface by assuming that any gas can only escape from the GASC.

198 The pressure is continuous at the GDL/GASC interface. 
For the aqueous species, we model them in the CL and the ELEC collectively. Mass fractions at the ELEC inlet (i.e. $y=0)$ are set according to those of the electrolyte feed. The aqueous mass flux at the CL/GDL interface is set to zero assuming no electrolyte leakage.

For the electronic potential, constant applied cathode potential, $V_{C}$ at the GDL/GASC interface is imposed for the 'GDL+CL' subdomain. In terms of the electrolyte potential, it is modelled within the 'CL+ELEC' subdomain together. The electrolyte potential, $\mathrm{V}_{\mathrm{l}}$ is set as zero (versus standard hydrogen electrode) ) $^{3,45-47}$ and zero-flux is applied at the CL/GDL boundary.

\subsection{Model-based performance evaluation}

In addition to current density and selectivity, the product yield (PY) and the specific electrical energy consumption (SEEC) should also be considered for scale-up analysis, because they are significant factors for the economic costs of an ECO2RR system. ${ }^{48}$ Assuming no losses of $\mathrm{HCOO}^{-}$, the PY is defined as the mass of formate produced per unit time and is given by:

$$
P Y=-\frac{a_{s l} M_{H C O O} W_{E} \int_{0}^{\mathrm{H}_{E}} \int_{0}^{L_{C L}} i_{E a} d x d y}{2 F}
$$

For the SEEC calculation, we only account for the electricity energy consumed by the electrolyser itself, excluding the consumption by the $\mathrm{CO}_{2}$ capture process, product purification and auxiliary units such as peristaltic pumps. The SEEC is defined as electric energy consumption for producing a unit mass of the formate product, and is calculated by:

$$
\mathrm{SEEC}=\frac{2 \mathrm{FV}_{\mathrm{app}}}{\mathrm{M}_{\mathrm{HCOO}} \mathrm{FE}_{\mathrm{HCOO}}}
$$

$\mathrm{V}_{\mathrm{app}}$ represents the required cell voltage and detailed calculation can be found in the SI section IV. 


\section{MUMPS general solver.}

\section{Model validation}

For the purpose of validation, the simulated total current density is converted to the overall superficial (geometrical) current density with respect to the cathode geometrical surface area, $\mathrm{i}_{\mathrm{C}}$ by: ${ }^{17}$

$$
\mathrm{i}_{\mathrm{C}}=\frac{\mathrm{a}_{\mathrm{sl}} \int_{0}^{\mathrm{H}_{\mathrm{E}}} \int_{0}^{\mathrm{L}_{\mathrm{CL}}}\left(\mathrm{i}_{\mathrm{Ea}}+\mathrm{i}_{\mathrm{Eb}}+\mathrm{i}_{\mathrm{Ec}}\right) \mathrm{dxdy}}{\mathrm{H}_{\mathrm{E}}}
$$

The Faraday efficiency (FE) is the important indicator representing the selectivity. The FEs for $\mathrm{HCOO}^{-}, \mathrm{CO}$ and $\mathrm{H}_{2}$ are defined as:

$$
\begin{gathered}
\mathrm{FE}_{\mathrm{HCOO}}=\frac{\mathrm{a}_{\mathrm{sl}} \int_{0}^{\mathrm{H}_{\mathrm{E}}} \int_{0}^{\mathrm{L}_{\mathrm{CL}}} \mathrm{i}_{\mathrm{Ea}} \mathrm{dxdy}}{\mathrm{i}_{\mathrm{C}} \mathrm{H}_{\mathrm{E}}} \times 100 \% \\
\mathrm{FE}_{\mathrm{CO}}=\frac{\mathrm{a}_{\mathrm{sl}} \int_{0}^{\mathrm{H}_{\mathrm{E}}} \int_{0}^{\mathrm{L}_{\mathrm{CL}}} \mathrm{i}_{\mathrm{Eb}} \mathrm{dxdy}}{\mathrm{i}_{\mathrm{C}} \mathrm{H}_{\mathrm{E}}} \times 100 \% \\
\mathrm{FE}_{\mathrm{H}_{2}}=\frac{\mathrm{a}_{\mathrm{sl}} \int_{0}^{\mathrm{H}_{\mathrm{E}}} \int_{0}^{\mathrm{L}_{\mathrm{CL}}} \mathrm{i}_{\mathrm{Ec}} \mathrm{dxdy}}{\mathrm{i}_{\mathrm{C}} \mathrm{H}_{\mathrm{E}}} \times 100 \%
\end{gathered}
$$

The experimental data and the detailed experiment setup can be found in the reference. ${ }^{4}$ As indicated by Figure 2 , the effects of electrolyte concentration and cathode potential on the $\mathrm{i}_{\mathrm{C}}$ and selectivity are predicted by our model with good fidelity at lower $\mathrm{KOH}$ concentrations (i.e. 0.5M). However, there is considerable departure between predicted values and experimental data at higher $\mathrm{KOH}$ concentrations (i.e. >1.0M), which could be attributed to: (i) $\mathrm{C}_{2}$ products (i.e. ethyl alcohol and ethylene) are notably generated at higher $\mathrm{KOH}$ concentration; ${ }^{4}$ (ii) the random error of total current density in experimental measurements enlarges with the $\mathrm{KOH}$ concentration higher than $0.5 \mathrm{M} ;{ }^{4}$ (iii) our steady-state model does not reflect the dynamic changes, such as the variation of catalyst size, composition and saturation condition and the effects of these factors tend to 

model based on a GDE experiment with $\mathrm{KHCO}_{3}$ as electrolyte ${ }^{4}$ has been conducted which further supports the general validity of the model (see SI section V). In the simulation studies presented below, the system with $\mathrm{KOH}$ as the electrolyte has been adopted since it would lead to higher current density and formate yield compared to a system using $\mathrm{KHCO}_{3}$ at the same concentration. ${ }^{4,12}$

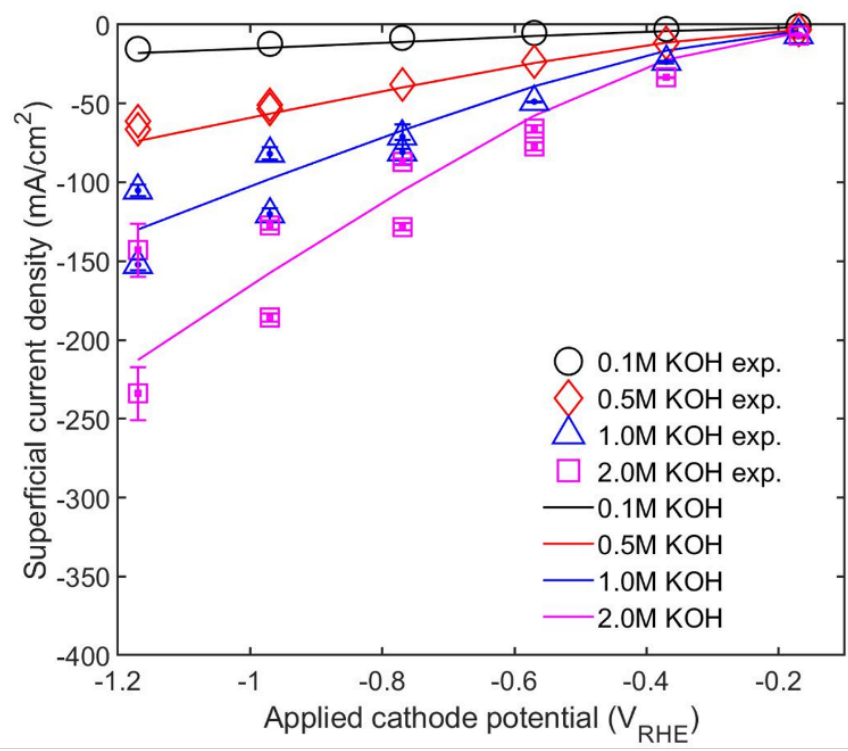

(a)

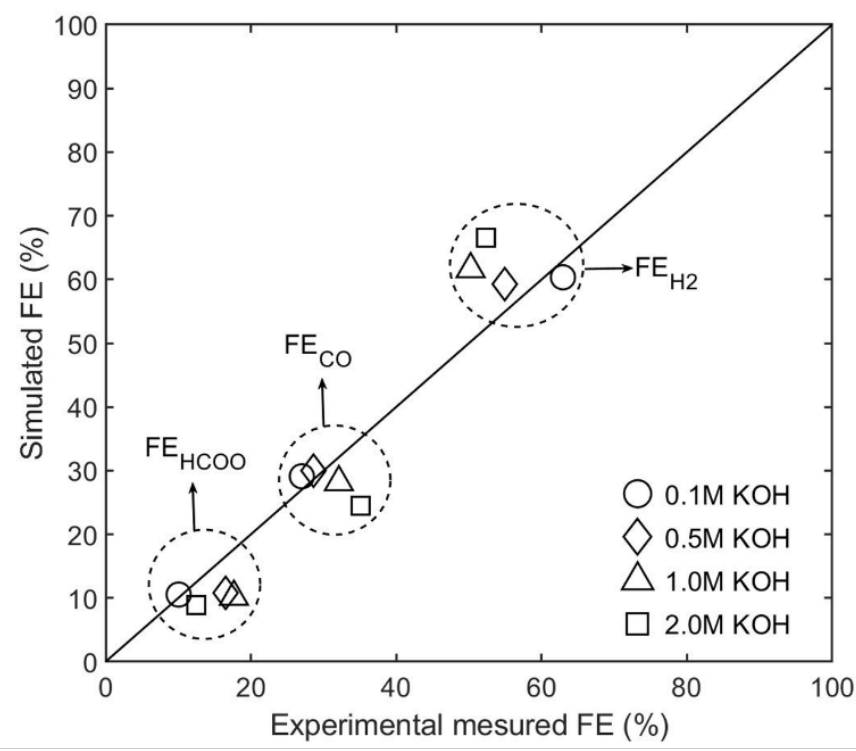

(b)

Figure 2 (a) Overall superficial current density with respect to the cathode geometrical surface area. The lower bound of experimental data of $0.5 \mathrm{M}, 1.0 \mathrm{M}$ and $2.0 \mathrm{M} \mathrm{KOH}$ are the measured overall superficial current density; the upper bound experimental data are the current density produced by the reaction ( $\mathrm{Ea}$ ) to (Ec) only; (b) Averaged selectivity from data for different cathode potential levels, with various $\mathrm{KOH}$ concentrations, compared with calibrated experimental data (excluding products other than $\mathrm{H}_{2}, \mathrm{CO}_{\text {and }} \mathrm{HCOO}^{-}$).

\section{Results and discussion}

Simulation results with various design and operational parameters are presented and interpreted in this section. In comparison with other $\mathrm{KOH}$ concentrations, the system with $0.5 \mathrm{M} \mathrm{KOH}$ catholyte and at the volumetric flowrate of $0.5 \mathrm{ml} / \mathrm{min}$ is selected as it could generate a higher current density and more formate under the 
same applied cathode potential, without contamination of C2 products. Unless stated otherwise, all other parameters remain as default (see SI Table S12) when the parametric study of a specific factor is carried out, and the description of current density change is in terms of its absolute value.

4.1. The effect of the applied cathode potential, $\mathrm{V}_{\mathrm{C}}$

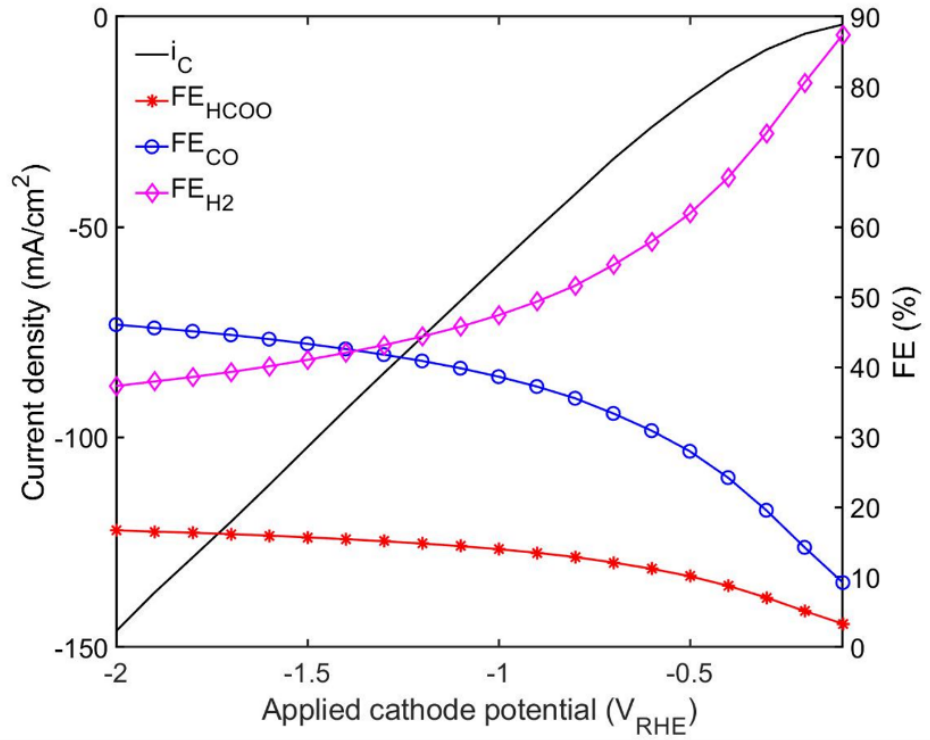

(a)

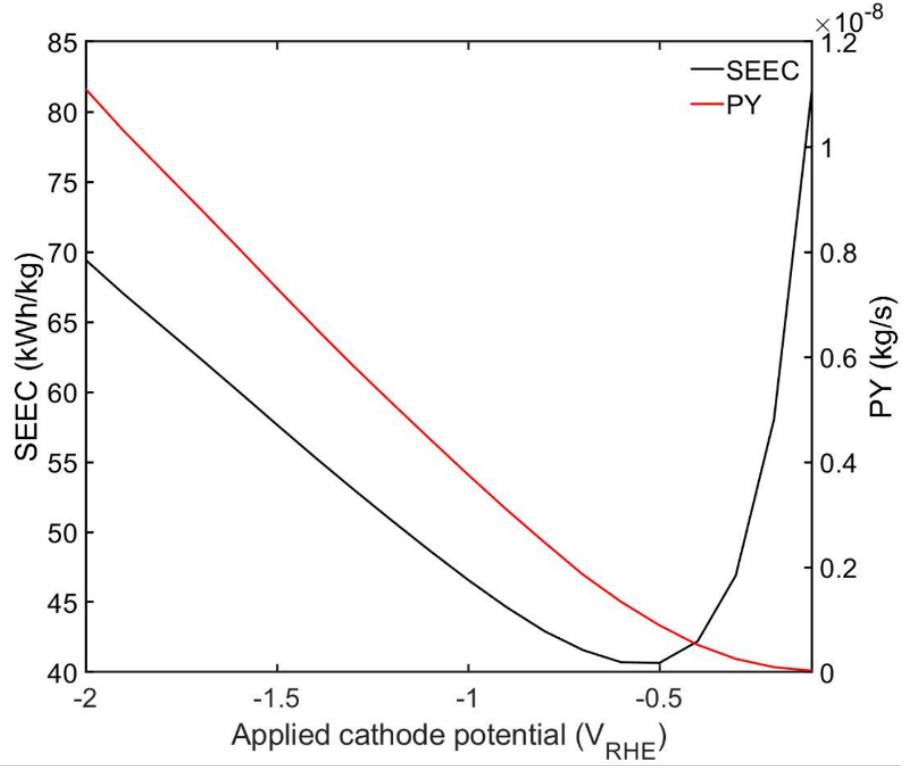

(b)

Figure 3 The effect of the applied cathode potential, $V_{c}$ on (a) overall superficial current density and selectivity; (b) PY and SEEC.

As shown in Figure $3(\mathrm{a})$, applied cathode potential, $\mathrm{V}_{\mathrm{C}}$ affects the cathodic overall superficial current density, $\mathrm{i}_{\mathrm{C}}$ and selectivity. As $\mathrm{V}_{\mathrm{C}}$ increases, the increases of $\mathrm{i}_{\mathrm{C}}$ (shown in Figure 3(a)) and partial current density for $\mathrm{HCOO}^{-}$, CO and $\mathrm{H}_{2}$ (not directly shown in Figure 3(a)) are expected (see Eqs. (19)-(21) and (29)). Owing to a smaller charge transfer coefficient and a significantly lower exchange current density of $\mathrm{HER}, \mathrm{FE}_{\mathrm{H}_{2}}$ continuously decreases with more negative $\mathrm{V}_{\mathrm{C}}$, which is desirable; however, $\mathrm{FE}_{\mathrm{CO}}$ increases faster than $\mathrm{FE}_{\mathrm{HCOO}}$ mainly because less negative $\mathrm{V}_{\mathrm{C}}$ is needed for accelerating $\mathrm{CO}_{2}$ conversion to $\mathrm{CO}$ than to $\mathrm{HCOO}^{-}$(i.e. $\mathrm{V}_{\text {eq,Eb }}$ is more positive than $V_{\text {eq,Ea }}$ ). Figure $3(\mathrm{~b})$ shows that $P Y$ is improved as $V_{C}$ becomes more negative, which is because of the increase in the partial current density for $\mathrm{HCOO}^{-}$. On SEEC, an optimal value of $\mathrm{V}_{\mathrm{C}}$ of $-0.5 \mathrm{~V}_{\mathrm{RHE}}$ exists; more negative $V_{C}$ beyond this point would lead to an increase in PY that cannot compensate the increase in the 

of $-0.5 \mathrm{~V}_{\mathrm{RHE}}$ is selected for other parametric studies use (unless specially mentioned).

\subsection{The GDE scalability}

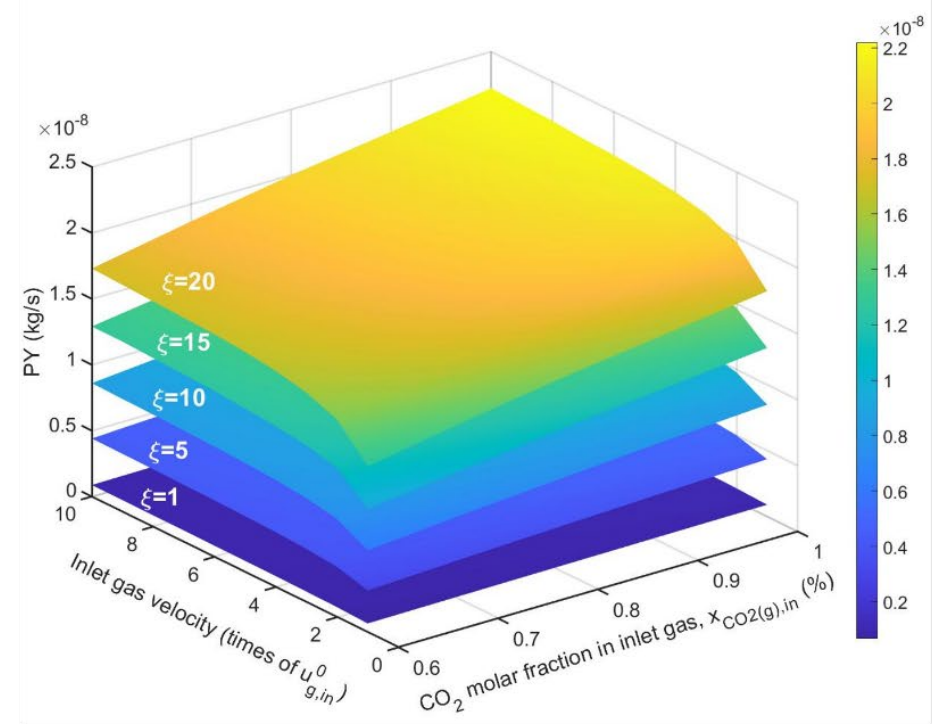

(a)

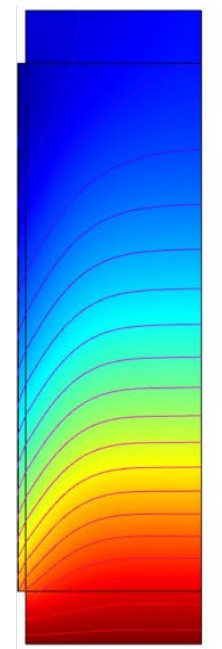

$\mathrm{u}_{\mathrm{g}, \mathrm{in}}^{0}$
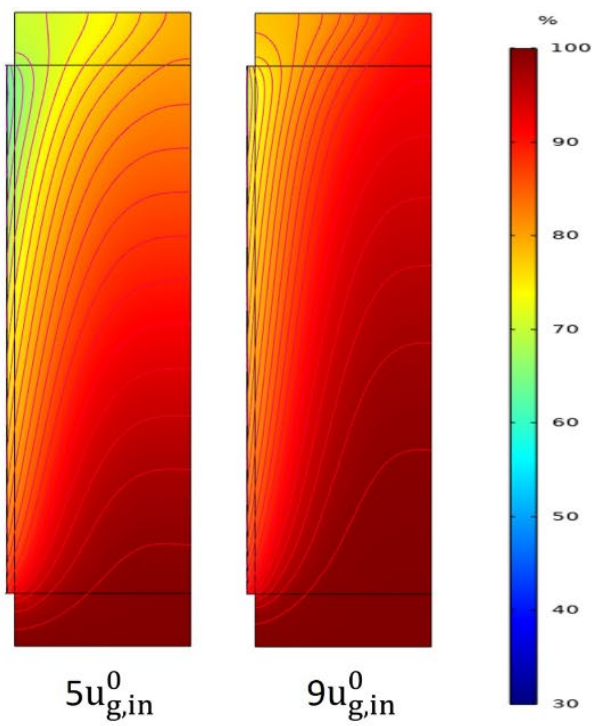

(b)

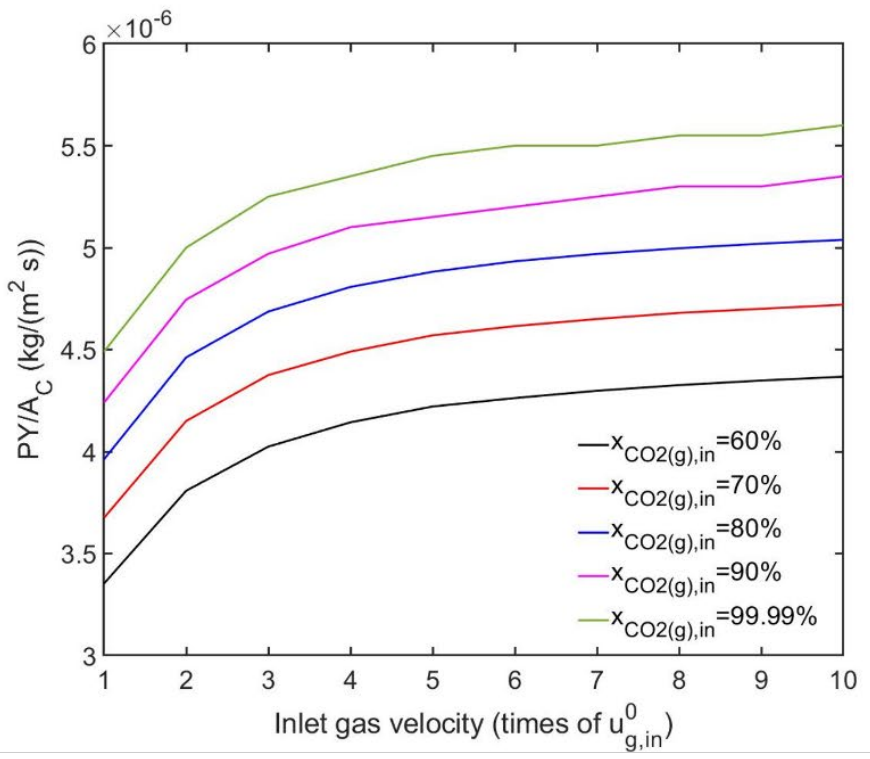

(c)

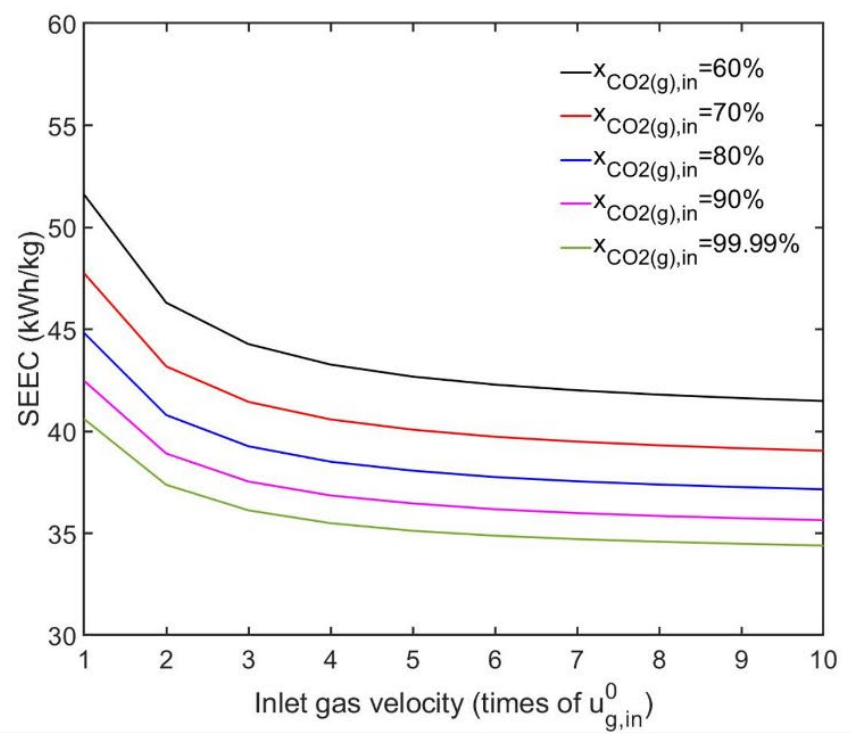

(d)

Figure 4 (a) PY with various inlet gas composition and velocity; (b) The distribution of $\mathrm{CO}_{2}$ molar fraction, $x_{\mathrm{CO}_{2}(g)}$ in the 'GASC+GDL+CL' subdomain with inlet gas velocity; (c) PY/Ac and (d) SEEC for the default system (i.e. $\xi=1$ ), as the function of inlet gas velocity and composition. 
Larger GDEs can to provide more reaction sites and therefore improve the product yield. To predict the performance of larger-sized GDEs, the cathode geometrical surface area, $\mathrm{A}_{\mathrm{C}}$ is upscaled by increasing electrode height, $\mathrm{H}_{\mathrm{E}}$ and width, $\mathrm{W}_{\mathrm{E}}$, while keeping the original aspect ratio (i.e. $\mathrm{H}_{\mathrm{E}} / \mathrm{W}_{\mathrm{E}}$ ). Note that when the thickness of each compartment remains unchanged, the volume of system scales together with $A_{C}$. The upscaling factor, $\xi$ is defined as:

$$
\xi=\frac{\text { Upscaled } A_{C}}{\text { Default } A_{C}}
$$

Two key indicators, PY and SEEC, are still employed to evaluate the performance of the upscaled system. The simulation results suggest that the GDE system is scalable for all the tested conditions (i.e. full tested range of gas velocity and molar fraction of $\mathrm{CO}_{2}$ in feed gas): (i) the PY is approximately scaled by the same factor of $\xi$ (shown in Figure 4(a) for illustration); (ii) the SEEC is comparable between the larger and smaller electrolysers (observed from simulation results, not shown here); (iii) the selectivity for each testing cases remains almost unchanged (observed from simulation results, not shown here). The first two observations are in accordance with the recently reported experiment finding. ${ }^{14}$

\subsection{The effect of inlet gas composition and velocity}

The impact of the inlet gas velocity, $\mathrm{u}_{\mathrm{g}, \mathrm{in}}$ and the molar fraction of $\mathrm{CO}_{2}(\mathrm{~g})$ in feed $g a s, \mathrm{x}_{\mathrm{CO}_{2}}(\mathrm{~g})$,in, as two operational settings easy to manipulate, has been discussed in several experimental studies ${ }^{9,12}$ and will be examined in this section from the perspective of modelling. For testing, the $\mathrm{u}_{\mathrm{g}, \mathrm{in}}$ is increased up to 10 times of the default value shown in SI Table S4, denoted here by $\mathrm{u}_{\mathrm{g}, \text { in }}^{0}$ and $\mathrm{x}_{\mathrm{CO}_{2}}(\mathrm{~g})$,in ranges from $60 \%$ to $99.99 \%$. Overall, as shown in Figure 4(a), increasing $\mathrm{CO}_{2}$ (g) supply, including higher $\mathrm{u}_{\mathrm{g} \text {,in }}$ and $\mathrm{x}_{\mathrm{CO}_{2}}(\mathrm{~g})$,in, is helpful to improve PY for different sizes of the GDE. The PY per $A_{C}, P Y / A_{C}$ and SEEC with various values of $u_{g, \text { in }}$ and $x_{C_{2}}(g)$,in for the default size of GDE (i.e. $\xi=1$ ) are further plotted in Figure 4(c) and (d). One can see that higher $\mathrm{x}_{\mathrm{CO}_{2}(\mathrm{~g}) \text {,in }}$ always 
improve both PY/A $\mathrm{C}$ and SEEC. As $\mathrm{u}_{\mathrm{g}, \text { in }}^{0}$ increases to $5 \mathrm{u}_{\mathrm{g}, \mathrm{in}}^{0}$, both PY/A $\mathrm{A}$ and the SEEC as well as the FE $\mathrm{HCOO}_{\text {(not }}$ shown) improve remarkably. However, this effect weakens as $u_{g, \text { in }}$ increases further. This is due to the tradeoff between $\mathrm{x}_{\mathrm{CO}_{2}(\mathrm{~g})}$ and total pressure in the $\mathrm{CL}$ : a larger $\mathrm{u}_{\mathrm{g} \text {,in }}$ elevates the $\mathrm{x}_{\mathrm{CO}_{2}(\mathrm{~g})}$ (shown in Figure $4(\mathrm{~b})$ ) but at the same time leads to a reduced total pressure in the CL (see SI figure S5(a)); the combined effect is gradually reduced increments of $\mathrm{CO}_{2}(\mathrm{~g})$ partial pressure and hence of the gas-liquid mass transfer rate for $\mathrm{CO}_{2}(\mathrm{~g})(\mathrm{see}$ SI figure S5(b)), eventually causing diminishing improvements to the production of formate. The effects of $u_{\mathrm{g}, \text { in }}$ and $\mathrm{x}_{\mathrm{CO}_{2}}(\mathrm{~g})$,in for other larger systems are similar.

\subsection{The effect of catalyst loading and arrangement}

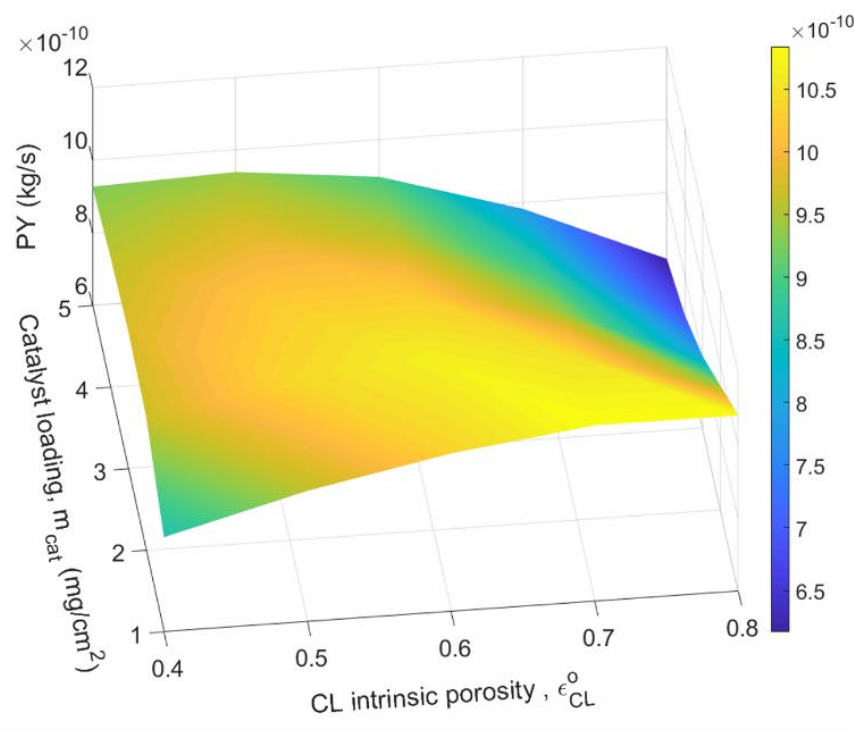

(a)

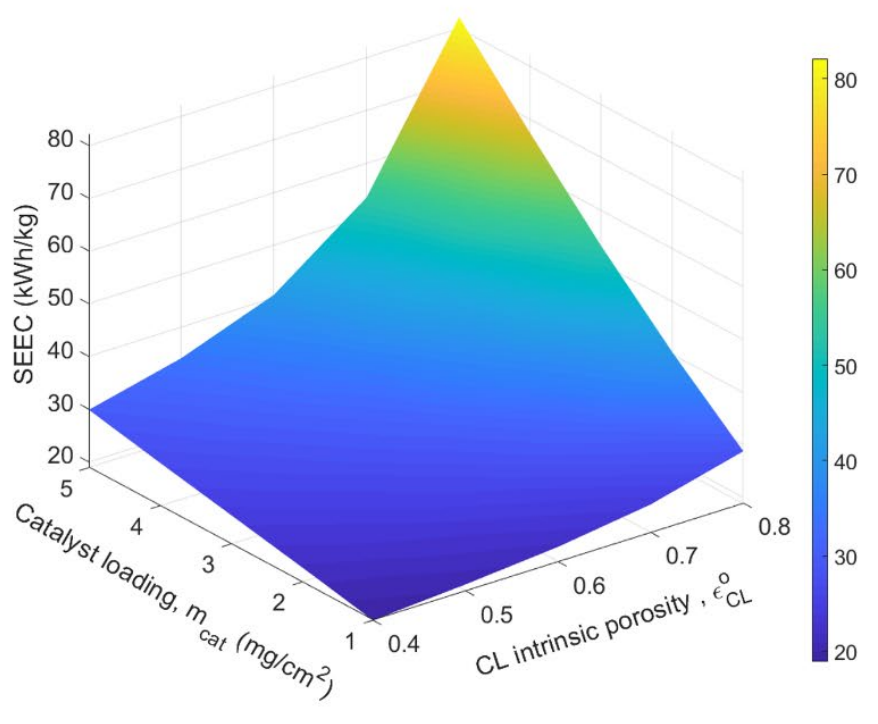

(b)

Figure 5 (a) PY and (b) SEEC with different catalyst amount and arrangement.

The catalyst amount and its arrangement can potentially affect both the performance and the cost of the ECO2RR system. In this section, the catalyst loading, $\mathrm{m}_{\text {cat }}$, and the catalyst arrangement represented by the intrinsic porosity in the $\mathrm{CL}, \epsilon_{\mathrm{CL}}^{\mathrm{o}}$ are discussed. Given the $\mathrm{CL}$ manufacture process, ${ }^{4}$ the parametric study for the intrinsic porosity in the $\mathrm{CL}, \epsilon_{\mathrm{CL}}^{\mathrm{o}}$ is conducted from 0.4 to 0.8 , which is in line with the porosity range of random packing arrangements of spherical grains. ${ }^{52}$ 
Figure 5(a) shows that the effect of $m_{\text {cat }}$ on PY varies for different values of $\epsilon_{\mathrm{CL}}^{\mathrm{o}}$, which reflects the trade-off between multiple factors including particularly $\mathrm{CO}_{2}$ supply and the provision of the active surface area for reactions. Based on Eq. (7), $\mathrm{L}_{\mathrm{CL}}$ would increase with $\mathrm{m}_{\text {cat }}$ when $\epsilon_{\mathrm{CL}}^{\mathrm{o}}$ is kept constant. On the one hand, for a larger $\mathrm{L}_{\mathrm{CL}}$ results in a longer path for gas diffusion (along with a greater ohmic loss of potential) which would lead to a lower $\mathrm{CO}_{2}(\mathrm{~g})$ partial pressure in the $\mathrm{CL}$ (see SI figure S6) and consequently a negative impact on formate generation. On the other hand, an increase of $m_{\text {cat }}$ provides a larger active surface for reactions, which potentially improves product generation (see Eq. (27)). For the $\mathrm{CL}$ with tighter packing (i.e. $\epsilon_{\mathrm{CL}}^{\mathrm{o}}<0.6$ ), the tradeoff of the above factors leads to the occurrence of optimal values of $m_{\text {cat }}$ corresponding to the maximum PY (i.e. $3 \mathrm{mg} / \mathrm{cm}^{2}$ for the $\mathrm{CL}$ with $\epsilon_{\mathrm{CL}}^{\mathrm{o}}=0.4$ and $2 \mathrm{mg} / \mathrm{cm}^{2}$ for the $\mathrm{CL}$ with $0.4<\epsilon_{\mathrm{CL}}^{\mathrm{o}}<0.6$ ). However, for the looser packing of the $\mathrm{CL}$ (i.e. $\epsilon_{\mathrm{CL}}^{\mathrm{O}}>0.6$ ), the losses associated with the increase thickness of the $\mathrm{CL}$ and outweighs the gains by the increase in the active surface area, therefore PY continuously drops with the increase in catalyst loading.

Analogous to the preceding analysis, the effect of $\epsilon_{\mathrm{CL}}^{\mathrm{o}}$ on PY is also a result of trade-offs. At a given $\mathrm{m}_{\mathrm{cat}}$, the change in $\epsilon_{\mathrm{CL}}^{\mathrm{O}}$ leads to a variation in $\mathrm{L}_{\mathrm{CL}}$ which impacts on $\mathrm{CO}_{2}$ supply as discussed above. Additionally, the effective diffusivity $\mathrm{D}_{\mathrm{CO}_{2}}^{\text {eff }}$ (g),CL (see Eqs. (5) and (6)) and active surface area for gas-liquid mass transfer, $\mathrm{a}_{\mathrm{gl}}$ (see Eq. (18)) augment with the increase in $\epsilon_{\mathrm{CL}}^{\mathrm{o}}$, which are instrumental to $\mathrm{CO}_{2}$ supply and subsequently to the PY. Furthermore, the larger active surface area for electrochemical reactions, $\mathrm{a}_{\mathrm{sl}}$ (see Eq. (26)) means more sites available for $\mathrm{CO}_{2}$ reduction process and can potentially increase PY (see Eq. (27)). Besides, $\epsilon_{\mathrm{CL}}^{\mathrm{O}}$ also affects conductivities: the reduced $\sigma_{\mathrm{S}, \mathrm{CL}}^{\text {eff }}$ owing to larger $\epsilon_{\mathrm{CL}}^{\mathrm{O}}$ would lead to a larger voltage drop, although this influence is negligible due to the relatively high value of $\sigma_{\mathrm{s}, \mathrm{CL}}^{\mathrm{eff}}$ in our case (confirmed by the simulation results, not shown here). The $\sigma_{\mathrm{l}, \mathrm{CL}}^{\text {eff }}$ on the other hand increases with a larger $\epsilon_{\mathrm{CL}}^{\mathrm{o}}$, but the electrolyte potential still drops significantly with the increased $L_{C L}$ and therefore could lead to more positive value of ' $V_{s}-V_{l}^{\prime}$ (observed from simulation results, not shown here), which is detrimental to $\mathrm{CO}_{2}$ reduction. With the combined effect of all the 
factors, the optimal $\epsilon_{\mathrm{CL}}^{\mathrm{o}}$ that leads to the maximum PY shifts from a higher value to a lower value as $\mathrm{m}_{\text {cat }}$ 328 increases.

329 To summarise, the effect of $\mathrm{m}_{\mathrm{cat}}$ and $\epsilon_{\mathrm{CL}}^{\mathrm{o}}$ on $\mathrm{PY}$ is shaped by multiple factors which, in combination, impact on 330 the local value of $i_{\mathrm{Ea}}$ and the overall surface area or volume of the CL. Overall, as shown in Figure 5(a), the 331 distribution of $1 \mathrm{mg} / \mathrm{cm}^{2}$ catalyst with the intrinsic porosity of 0.7 for the $\mathrm{CL}$, i.e. a design with a low catalyst 332 loading within a "spacious" arrangement, is capable to gain the highest PY (i.e. $1.08 \times 10^{-9} \mathrm{~kg} / \mathrm{s}$ ) within the 333 tested range of settings.

Different from the PY, Figure 5(b) shows that the SEEC always increases with $\epsilon_{\mathrm{CL}}^{\mathrm{o}}$ and $\mathrm{m}_{\text {cat }}$, suggesting a more "compact" $\mathrm{CL}$ is preferable. The least favourable design in terms of the SEEC (featuring largest $\epsilon_{\mathrm{CL}}^{\mathrm{o}}$ and $\mathrm{m}_{\mathrm{cat}}$ ) coincides with that in terms of the PY, but the optimal setting for the SEEC (featuring lowest $\epsilon_{\mathrm{CL}}^{\mathrm{o}}$ and $\mathrm{m}_{\mathrm{cat}}$ ) corresponds to that leading to an intermediate PY. This is a result of the compromise between the PY and the total energy consumption; the latter is dictated by the larger overpotentials at higher overall currents.

\section{Conclusion}

In this paper, gas diffusion electrode (GDE)-based electrochemical conversion of $\mathrm{CO}_{2}$ to formate together with the by-products (i.e. $\mathrm{CO}$ and $\mathrm{H}_{2}$ ) was modelled. The two-dimensional steady-state multiphase model was developed by incorporating electrochemical kinetics, the kinetics of homogeneous (aqueous-phase) reactions and transport phenomena in the cathode compartment. This model demonstrated a good agreement with experimental data of current density and selectivity for the system with lower concentrations of $\mathrm{KOH}$ and was employed to investigate the effect of applied cathode potential, inlet gas composition and velocity as well as catalyst loading and arrangement on product yield (PY) and specific electrical energy consumption (SEEC). 
The simulation results have shown that a more negative cathodic potential results in a higher PY, while the lowest SEEC is reached at an optimal level of $-0.5 \mathrm{~V}_{\mathrm{RHE}}$ with the default settings. The GDE was predicted to be scalable in terms of its cathode geometrical surface area, with respect to selectivity, PY and SEEC. On the impact of design and operational parameters, we have shown that both the PY and the SEEC can be improved by better $\mathrm{CO}_{2}$ supply through a higher $\mathrm{CO}_{2}$ feed concentration or a greater gas flowrate, although the improvement by the latter becomes insignificant beyond a certain level as the impact of reduced total pressure amplifies. The PY was shown to be shaped by multiple factors when catalyst loading and arrangement are changed. Resulting from the trade-offs between mass transfer resistance, ohmic loss and effective areas available for mass transfer and reactions, dispersion of $1 \mathrm{mg} / \mathrm{cm}^{2}$ catalysts with the porosity of 0.7 in the $\mathrm{CL}$, representing a low loading with a sparse arrangement of catalyst particles, was predicted to be optimal to gain the maximum PY in our study. For the SEEC, its value always becomes larger with $\mathrm{m}_{\mathrm{cat}}$ and $\epsilon_{\mathrm{CL}}^{\mathrm{o}}$ resulting from the compromise between the increase in the PY and the increase in overpotential losses, suggesting that higher energy efficiencies may prefer a more compact (i.e. thin and dense) catalyst layer.

Overall, our work demonstrates that a GDE-based device for converting $\mathrm{CO}_{2}$ with formate as a desirable product has good potential for upscaling, and its performance can be significantly improved by choosing the optimal design and operating settings. These learnings may be applicable to other GDE-based ECO2RR applications. In the future, more efforts could be made to develop a dynamic model to capture further details and integrate with techno-economic analysis and life cycle analysis to gain a holistic understanding of such systems.

Supporting information

Source terms in the CL; key parameter values; specific electrical energy consumption (SEEC); model validation; testing parameter data; profiles of pressure, molar fraction and gas-liquid mass transfer rate. 
369 There are no conflicts to declare.

Acknowledgements

Ziming Yang thanks the China Scholarship Council (CSC) to support her PhD study. The work is supported by the EPSRC LifesCO2R project (EP/N009746/1), the EPSRC NECEM (EP EP/R021503/1), the NERC MeteoRR (NE/L014246/1) and the Open Fund Project of State Key Laboratory of Clean Energy Utilization Project No: ZJUCEU2019004.

375 Nomenclature

$\begin{array}{cl}\text { Symbol } & \\ \mathrm{H}_{\mathrm{CO}_{2}} & \text { Henry's constant for } \mathrm{CO}_{2}, \mathrm{~Pa} \mathrm{M}^{-1} \\ \mathrm{~K}_{\mathrm{GL}} & \text { Overall mass transfer coefficient, } \mathrm{m} \mathrm{s}^{-1} \\ \mathrm{R}_{\mathrm{ideal}} & \text { Ideal gas constant, } \mathrm{J} \mathrm{mol}^{-1} \mathrm{~K}^{-1} \\ \mathrm{a} & \text { Specific interfacial area, } \mathrm{m}^{-1} \\ \mathrm{~A} & \text { Area, } \mathrm{m}^{2} \\ \mathrm{C} & \text { Concentration, } \mathrm{M} \\ \mathrm{d} & \text { Diameter, } \mathrm{m} \\ \mathrm{D} & \text { Molecular diffusivity, } \mathrm{m}^{2} \mathrm{~s}^{-1} \\ \mathrm{~F} & \text { Faraday constant, } \mathrm{s} \mathrm{A} \mathrm{mol}{ }^{-1} \\ \mathrm{FE} & \text { Faraday efficiency, } \% \\ \mathrm{~g} & \text { Gravitational acceleration, } \mathrm{m} \mathrm{s}^{-2} \\ \mathrm{H} & \text { Height (y-axis), } \mathrm{m} \\ \mathrm{i} & \text { Current density, A m } \\ \mathrm{k} & \text { Reaction rate constant, } \mathrm{M}^{-1} \mathrm{~s}^{-1} \\ \mathrm{~K} & \text { Equilibrium constant, } \mathrm{M}^{-1} \\ \mathrm{~L} & \text { Thickness (x-axis) or distance, } \mathrm{m}\end{array}$




\begin{tabular}{|c|c|}
\hline $\mathrm{m}$ & Mass loading, $\mathrm{kg} \mathrm{m}^{-2}$ \\
\hline M & Molar weight, $\mathrm{kg} \mathrm{mol}^{-1}$ \\
\hline $\mathrm{n}$ & Number of transferred electrons, dimensionless \\
\hline $\mathrm{P}$ & Pressure, $\mathrm{Pa}$ \\
\hline PY & Product (i.e. formate) yield, $\mathrm{kg} \mathrm{s}^{-1}$ \\
\hline Q & Source term, its unit relying on the specific reactions \\
\hline $\mathrm{q}$ & Volumetric flowrate, $\mathrm{m}^{3} \mathrm{~s}^{-1}$ \\
\hline $\mathrm{R}$ & Volumetric reaction rate on the mass basis, $\mathrm{kg} \mathrm{m}^{-3} \mathrm{~s}^{-1}$ \\
\hline $\mathrm{r}$ & Radius, m \\
\hline $\mathrm{S}$ & Saturation coefficient, dimensionless \\
\hline SEEC & Specific electrical energy consumption, $\mathrm{kWh} k g$ (formate) $^{-1}$ \\
\hline $\mathrm{T}$ & Operating temperature, $\mathrm{K}$ \\
\hline $\mathrm{u}$ & Velocity, $\mathrm{m} \mathrm{s}^{-1}$ \\
\hline $\mathrm{V}$ & Potential, V \\
\hline W & Width, m \\
\hline $\mathrm{x}$ & Molar fraction, dimensionless \\
\hline $\mathrm{Z}$ & Valence of ionic species \\
\hline$\beta$ & Symmetry factor, dimensionless \\
\hline$\delta$ & Thickness, m \\
\hline$\epsilon$ & Porosity, dimensionless \\
\hline$\kappa$ & Permeability, $\mathrm{m}^{2}$ \\
\hline$\mu$ & Dynamic viscosity, Pa s \\
\hline$\xi$ & Scale-up factor, dimensionless \\
\hline$\rho$ & Density, $\mathrm{kg} \mathrm{m}^{-3}$ \\
\hline$\sigma$ & Conductivity, $\mathrm{S} \mathrm{m}^{-1}$ \\
\hline$\omega$ & Mass fraction, dimensionless \\
\hline \multicolumn{2}{|l|}{ Subscript } \\
\hline app & Applied/required external potential \\
\hline $\mathrm{aq}$ & Dissolved species \\
\hline $\mathrm{b}$ & Bulk phase \\
\hline $\mathrm{C}$ & Cathode \\
\hline
\end{tabular}




\begin{tabular}{|c|c|}
\hline cat & Catalyst \\
\hline CL & Catalyst layer \\
\hline $\mathrm{d}$ & Diffusion \\
\hline $\mathrm{E}$ & Electrode \\
\hline $\mathrm{Ea}$ & Electrochemical reaction, Ea \\
\hline $\mathrm{Eb}$ & Electrochemical reaction, Eb \\
\hline Ec & Electrochemical reaction, Ec \\
\hline ele & Electrolyte \\
\hline ELEC & Electrolyte channel \\
\hline $\mathrm{eq}$ & Equilibrium \\
\hline EXT & Extension \\
\hline $\mathrm{g}$ & Mixture gas \\
\hline GASC & Gas chamber \\
\hline GDL & Gas diffusion layer \\
\hline $\mathrm{H}$ & Homogeneous reactions \\
\hline $\mathrm{Ha}$ & Homogeneous reaction, $\mathrm{Ha}$ \\
\hline $\mathrm{Hb}$ & Homogeneous reaction, $\mathrm{Hb}$ \\
\hline $\mathrm{i}$ & Gaseous species \\
\hline in & Inlet gas \\
\hline $\mathrm{j}$ & Aqueous species \\
\hline $\mathrm{k}$ & Gaseous species, $\mathrm{k} \neq \mathrm{i}$ \\
\hline $\mathrm{m}$ & Medium \\
\hline o & Exchange current density \\
\hline $\mathrm{P}$ & Gas-liquid mass transfer \\
\hline $\mathrm{p}$ & Porous \\
\hline RHE & Reversible hydrogen electrode \\
\hline s & Electronic (solid material) potential \\
\hline \multicolumn{2}{|l|}{ Superscript } \\
\hline 0 & Intrinsic characteristics \\
\hline eff & Effective characteristics \\
\hline o & Theoretical value \\
\hline
\end{tabular}




\begin{tabular}{cl}
\hline ref & Reference condition \\
\hline Abbreviation & Carbon capture and utilisation \\
CL & Catalyst layer \\
ECO2RR & Electrochemical $\mathrm{CO}_{2}$ reduction reaction \\
ELEC & Electrolyte channel \\
FE & Faraday efficiency \\
GASC & Gas chamber \\
GDE & Gas diffusion electrode \\
GDL & Gas diffusion layer \\
HER & Hydrogen evolution reaction \\
LHS & Left-hand side (of an equation) \\
MEAs & Membrane-electrode-assemblies \\
PY & Product yield \\
RDS & Rate-determining step \\
SEEC & Specific electrical energy consumption \\
\hline
\end{tabular}

376 References

377 (1) Nguyen, T. N.; Dinh, C. T. Gas Diffusion Electrode Design for Electrochemical Carbon Dioxide Reduction. Chem. Soc. Rev. 2020, 49, 7488-7504.

(2) García de Arquer, F. P.; Dinh, C. T.; Ozden, A.; Wicks, J.; McCallum, C.; Kirmani, A. R.; Nam, D. H.; Gabardo, C.; Seifitokaldani, A.; Wang, X.; Li, Y. C.; Li, F.; Edwards, J.; Richter, L. J.; Thorpe, S. J.; Sinton, D.; Sargent, E. H. CO2 Electrolysis to Multicarbon Products at Activities Greater than 1 A Cm-2. Science. 2020, 367, 661-666.

(3) Weng, L. C.; Bell, A. T.; Weber, A. Z. Modeling Gas-Diffusion Electrodes for CO2 Reduction. Phys. Chem. Chem. Phys. 2018, 20, 16973-16984.

(4) Xiang, H.; Rasul, S.; Scott, K.; Portoles, J.; Cumpson, P.; Yu, E. H. Enhanced Selectivity of Carbonaceous 
Products from Electrochemical Reduction of CO2 in Aqueous Media. J. CO2 Util. 2019, 30, 214-221.

(5) Lu, X.; Leung, D. Y. C.; Wang, H.; Leung, M. K. H.; Xuan, J. Electrochemical Reduction of Carbon Dioxide to Formic Acid. ChemElectroChem 2014, 1, 836-849.

(6) Newman, J.; Tiedemann, W. Porous-electrode Theory with Battery Applications. AlChE J. 1975, 21 (1), 25-41.

(7) Liang, S.; Altaf, N.; Huang, L.; Gao, Y.; Wang, Q. Electrolytic Cell Design for Electrochemical CO2 Reduction. J. CO2 Util. 2020, 35, 90-105.

(8) De Mot, B.; Hereijgers, J.; Duarte, M.; Breugelmans, T. Influence of Flow and Pressure Distribution inside a Gas Diffusion Electrode on the Performance of a Flow-by CO2 Electrolyzer. Chem. Eng. J. 2019, 378, 122224.

(9) Tan, Y. C.; Lee, K. B.; Song, H.; Oh, J. Modulating Local CO2 Concentration as a General Strategy for Enhancing C-C Coupling in CO2 Electroreduction. Joule 2020, 4, 1104-1120.

(10) Whipple, D. T.; Kenis, P. J. A. Prospects of CO2 Utilization via Direct Heterogeneous Electrochemical Reduction. J. Phys. Chem. Lett. 2010, 1, 3451-3458.

(11) Lee, M. Y.; Park, K. T.; Lee, W.; Lim, H.; Kwon, Y.; Kang, S. Current Achievements and the Future Direction of Electrochemical CO2 Reduction: A Short Review. Crit. Rev. Environ. Sci. Technol. 2020, 50 (8), 769-815.

(12) Gabardo, C. M.; O’Brien, C. P.; Edwards, J. P.; McCallum, C.; Xu, Y.; Dinh, C. T.; Li, J.; Sargent, E. H.; Sinton, D. Continuous Carbon Dioxide Electroreduction to Concentrated Multi-Carbon Products Using a Membrane Electrode Assembly. Joule 2019, 3, 2777-2791.

(13) Li, H.; Oloman, C. Development of a Continuous Reactor for the Electro-Reduction of Carbon Dioxide to Formate - Part 2: Scale-Up. J. Appl. Electrochem. 2007, 37, 1107-1117. 
(14) Jeanty, P.; Scherer, C.; Magori, E.; Wiesner-Fleischer, K.; Hinrichsen, O.; Fleischer, M. Upscaling and Continuous Operation of Electrochemical CO2 to CO Conversion in Aqueous Solutions on Silver Gas Diffusion Electrodes. J. CO2 Util. 2018, 24, 454-462.

(15) Krause, R.; Reinisch, D.; Reller, C.; Eckert, H.; Hartmann, D.; Taroata, D.; Wiesner-Fleischer, K.; Bulan, A.; Lueken, A.; Schmid, G. Industrial Application Aspects of the Electrochemical Reduction of CO2 to CO in Aqueous Electrolyte. Chemie-Ingenieur-Technik 2020, 92, 53-61.

(16) Wang, H.; Leung, D. Y. C.; Xuan, J. Modeling of a Microfluidic Electrochemical Cell for CO2 Utilization and Fuel Production. Appl. Energy 2013, 102, 1057-1062.

(17) Wu, K.; Birgersson, E.; Kim, B.; Kenis, P. J. A.; Karimi, I. A. Modeling and Experimental Validation of Electrochemical Reduction of CO2 to CO in a Microfluidic Cell. J. Electrochem. Soc. 2015, 162 (1), F23F32.

(18) Georgopoulou, C.; Jain, S.; Agarwal, A.; Rode, E.; Dimopoulos, G.; Sridhar, N.; Kakalis, N. On the Modelling of Multidisciplinary Electrochemical Systems with Application on the Electrochemical Conversion of CO2 to Formate/Formic Acid. Comput. Chem. Eng. 2016, 93, 160-170.

(19) Weng, L. C.; Bell, A. T.; Weber, A. Z. Towards Membrane-Electrode Assembly Systems for CO2 Reduction: A Modeling Study. Energy Environ. Sci. 2019, 12, 1950-1968.

(20) Weng, L.-C.; Bell, A. T.; Weber, A. Z. A Systematic Analysis of Cu-Based Membrane-Electrode Assemblies for CO2 Reduction through Multiphysics Simulation. Energy Environ. Sci. 2020, 13, 3592-3606.

(21) Garg, S.; Li, M.; Weber, A. Z.; Ge, L.; Li, L.; Rudolph, V.; Wang, G.; Rufford, T. E. Advances and Challenges in Electrochemical CO2 Reduction Processes: An Engineering and Design Perspective Looking beyond New Catalyst Materials. J. Mater. Chem. A 2020, 8, 1511-1544.

(22) Zhong, H.; Fujii, K.; Nakano, Y.; Jin, F. Effect of CO2 Bubbling into Aqueous Solutions Used for 
61.

(23) Hori, Y.; Murata, A.; Takahashi, R. Formation of Hydrocarbons in the Electrochemical Reduction of Carbon Dioxide at a Copper Electrode in Aqueous Solution. J. Chem. Soc. Faraday Trans. 1 Phys. Chem. Condens. Phases 1989, 85 (8), 2309-2326.

(24) Hori, Y.; Suzuki, S. Electrolytic Reduction of Bicarbonate Ion at a Mercury Electrode. J. Electrochem. Soc. 1983, 130, 2387.

(25) Kumar, B.; Llorente, M.; Froehlich, J.; Dang, T.; Sathrum, A.; Kubiak, C. P. Photochemical and Photoelectrochemical Reduction of CO2. Annu. Rev. Phys. Chem. 2012, 63, 541-569.

(26) Haas, T.; Krause, R.; Weber, R.; Demler, M.; Schmid, G. Technical Photosynthesis Involving CO2 Electrolysis and Fermentation. Nat. Catal. 2018, 1, 32-39.

(27) Ma, S.; Sadakiyo, M.; Luo, R.; Heima, M.; Yamauchi, M.; Kenis, P. J. A. One-Step Electrosynthesis of Ethylene and Ethanol from CO2 in an Alkaline Electrolyzer. J. Power Sources 2016, 301, 219-228.

(28) Qiao, J.; Fan, M.; Fu, Y.; Bai, Z.; Ma, C.; Liu, Y.; Zhou, X. D. Highly-Active Copper Oxide/Copper Electrocatalysts Induced from Hierarchical Copper Oxide Nanospheres for Carbon Dioxide Reduction Reaction. Electrochim. Acta 2015, 153, 559-565.

(29) Kotb, Y.; Fateen, S. E. K.; Albo, J.; Ismail, I. Modeling of a Microfluidic Electrochemical Cell for the Electro-Reduction of $\mathrm{CO} 2$ to $\mathrm{CH} 3 \mathrm{OH}$. J. Electrochem. Soc. 2017, 164 (13), E391-E400.

(30) J.Kee, R.; Coltrin, M. E.; Glarborg, P.; Zhu, H. Chemically Reacting Flow; 2003.

(31) Torstensson, M. A Comparison of the Multicomponent Model and the Mixture Averaged Approximation, 2014.

(32) Bongers, H.; De Goey, L. P. H. The Effect of Simplified Transport Modeling on the Burning Velocity of 
Laminar Premixed Flames. Combust. Sci. Technol. 2003, 175, 1915-1928.

453

454

455

456

457

458

459

460

461

462

463

464

465

466

467

468

469

470

471

472

473

(33) Balliet, R. J.; Newman, J. Cold Start of a Polymer-Electrolyte Fuel Cell I. Development of a Two-

Dimensional Model. J. Electrochem. Soc. 2011, 158 (8), B927-B938.

(34) Serincan, M. F.; Pasaogullari, U.; Sammes, N. M. Effects of Operating Conditions on the Performance of a Micro-Tubular Solid Oxide Fuel Cell (SOFC). J. Power Sources 2009, 192, 414-422.

(35) Bear, J. Dynamics of Fluids in Porous Media; Amerian Elsevier publishing company, 1972.

(36) M. Kaviany. Principles of Heat Transfer in Porous Media, Second edi.; Springer: New York, 1999.

(37) Nam, J. H.; Kaviany, M. Effective Diffusivity and Water-Saturation Distribution in Single- and Two-Layer PEMFC Diffusion Medium. Int. J. Heat Mass Transf. 2003, 46, 4595-4611.

(38) Weber, A. Z.; Newman, J. Modeling Transport in Polymer-Electrolyte Fuel Cells. Chem. Rev. 2004, 104 (10), 4679-4726.

(39) Zhang, B.; Ye, D. D.; Sui, P. C.; Djilali, N.; Zhu, X. Computational Modeling of Air-Breathing Microfluidic Fuel Cells with Flow-over and Flow-through Anodes. J. Power Sources 2014, 259, 15-24.

(40) Mo, Z.; Friedly, J. C. Local Reaction and Diffusion in Porous Media Transport Models. Water Resour. researcch 2000, 36 (2), 431-438.

(41) Cheng, T.; Xiao, H.; Goddard, W. A. Reaction Mechanisms for the Electrochemical Reduction of CO2 to $\mathrm{CO}$ and Formate on the $\mathrm{Cu}(100)$ Surface at $298 \mathrm{~K}$ from Quantum Mechanics Free Energy Calculations with Explicit Water. J. Am. Chem. Soc. 2016, 138, 13802-13805.

(42) Wei, J.; Zhou, M.; Long, A.; Xue, Y.; Liao, H.; Wei, C.; Xu, Z. J. Heterostructured Electrocatalysts for Hydrogen Evolution Reaction under Alkaline Conditions. Nano-Micro Lett. 2018, 10:75.

(43) Bernardi, Dawn M., Verbrugge, M. W. Mathematical Model of a Gas Diffusion Electrode Bonded to a Polymer Electrolyte. AIChE J. 1991, 37 (8), 1151-1163. 
(44) Xing, L.; Mamlouk, M.; Kumar, R.; Scott, K. Numerical Investigation of the Optimal Nafion ${ }^{\circledR}$ Ionomer Content in Cathode Catalyst Layer: An Agglomerate Two-Phase Flow Modelling. Int. J. Hydrogen Energy 2014, 39, 9087-9104.

(45) Björnbom, P. Influence of Diffusion Resistances on Gas Diffusion Electrodes. J. Electrochem. Soc. 1986, $133(9), 1874-1875$.

(46) Buck, R. P. Kinetics of Bulk and Interfacial Ionic Motion: Microscopic Basis and Limits for the NernstPlanck Equation Applied to Membrane Systems. J. Memb. Sci. 1984, 17, 1-62.

(47) Baker, D. R. Reducing Nonlinear Systems of Transport Equations to Laplace's Equation. SIAM J. Appl. Math. 1993, 53 (2), 419-439.

(48) Spurgeon, J. M.; Kumar, B. A Comparative Technoeconomic Analysis of Pathways for Commercial Electrochemical CO2 Reduction to Liquid Products. Energy Environ. Sci. 2018, 11, 1536-1551.

(49) Xiang, H.; Miller, H. A.; Bellini, M.; Christensen, H.; Scott, K.; Rasul, S.; Yu, E. H. Production of Formate by CO2 Electrochemical Reduction and Its Application in Energy Storage. Sustain. Energy Fuels 2019, 4, 277-284.

(50) Endrődi, B.; Bencsik, G.; Darvas, F.; Jones, R.; Rajeshwar, K.; Janáky, C. Continuous-Flow Electroreduction of Carbon Dioxide. Prog. Energy Combust. Sci. 2017, 62, 133-154.

(51) Xiang, H.; Rasul, S.; Hou, B.; Portoles, J.; Cumpson, P.; Yu, E. H. Copper-Indium Binary Catalyst on a Gas Diffusion Electrode for High-Performance CO2 Electrochemical Reduction with Record CO Production Efficiency. ACS Appl. Mater. Interfaces 2020, 12, 601-608.

(52) Gueguen, Y.; Victor Palciauskas. Introduction to the Physics of Rocks; Princeton university press: Princeton, 1994. 


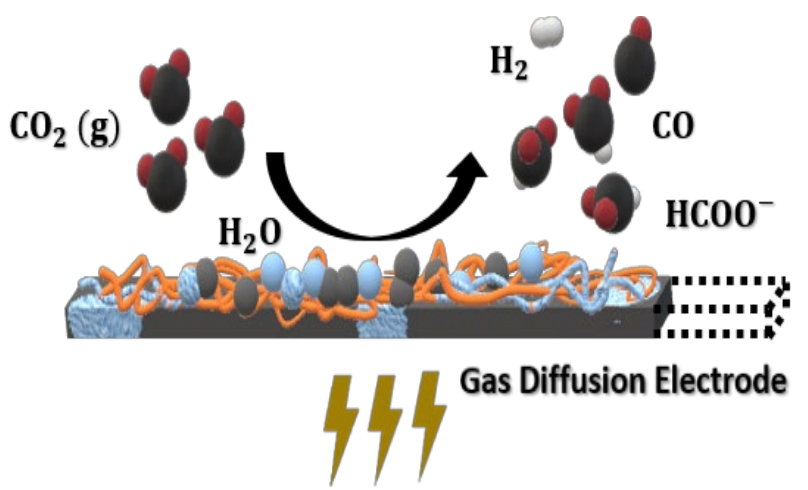

Figure 6 For Table of Contents Use Only

Synopsis

500

Electrochemical $\mathrm{CO}_{2}$ reduction systems incorporating gas diffusion electrodes have the potential to transform $\mathrm{CO}_{2}$ to valuable products efficiently and environment-friendly. 